\title{
Discovery of Highly Specific Catalytic-Site-Targeting Fluorescent Probes for Detecting Lysosomal PDE10A in \\ Living Cells
}

Yuqi $\mathrm{Gao}^{+}$, Ju Huang ${ }^{\dagger}$, Qian Zhou ${ }^{\dagger}$, Runduo Liu', Sirui Zhang ${ }^{\dagger}$, Chen Zhang ${ }^{\dagger}$, Yi-You Huang',

$\mathrm{Zhe} \mathrm{Li}^{\dagger}$, Ling Huang ${ }^{\dagger}$, Deyan $\mathrm{Wu}^{\dagger}$, Yinuo $\mathrm{Wu}^{\dagger}$, Lehui Xiao ${ }^{\ddagger}$, Lei Guo ${ }^{*,+}$, and Hai-Bin Luo ${ }^{*,+}$

\footnotetext{
† School of Pharmaceutical Sciences, Sun Yat-sen University, Guangzhou 510006, China

* State Key Laboratory of Medicinal Chemical Biology, Tianjin Key Laboratory of Biosensing and Molecular Recognition, College of Chemistry, Nankai University, Tianjin 300071, China
}

\section{Contents}

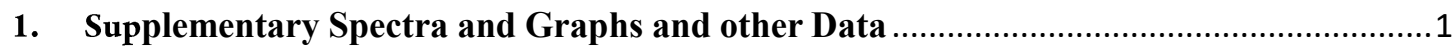

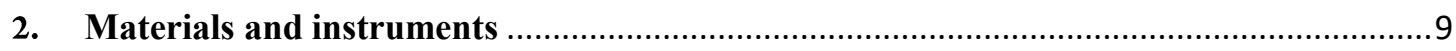

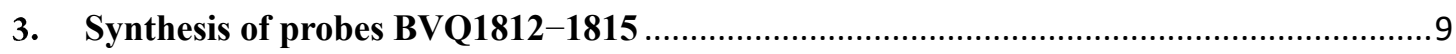

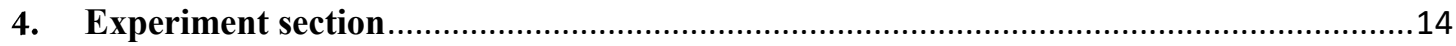

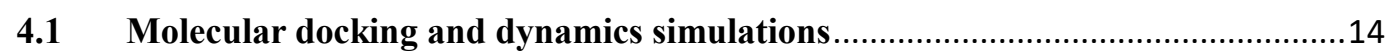

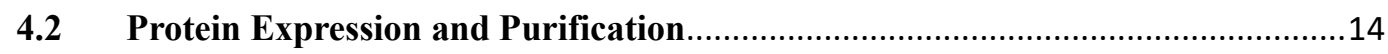

4.3 Fluorescent excitation and emission spectra of BVQ1812-1815 ….......................14

4.4 The fluorescence quantum yield and pKa measurements ...................................15

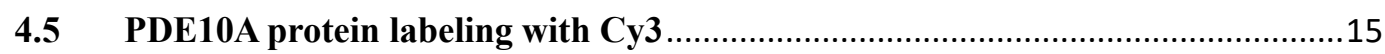

4.6 Fluorescence properties of BVQ1814 with PDE10A recombinant protein ..........16

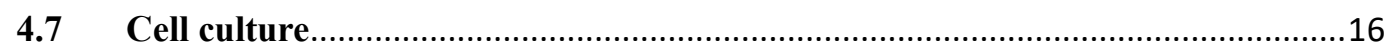

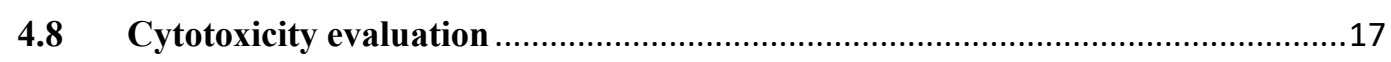

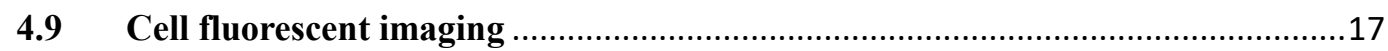

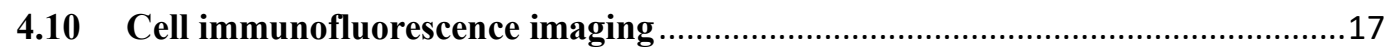

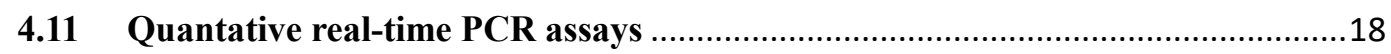

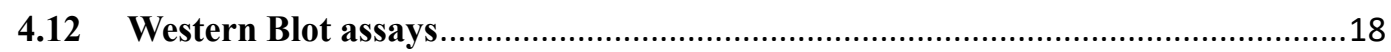

4.13 Cells transiently transfected with PDE10A siRNA …........................................18

4.14 Construction of stable transfected PDE10A overexpressing HepG2 cells.............19

4.15 Preparation of primary pulmonary artery smooth muscle cells..........................19

4.16 Tissue sections immunofluorescent imaging ....................................................20

4.17 Pharmacodynamics study for the pharmacology on animal models .....................20

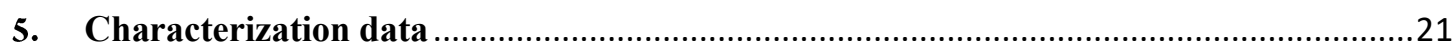

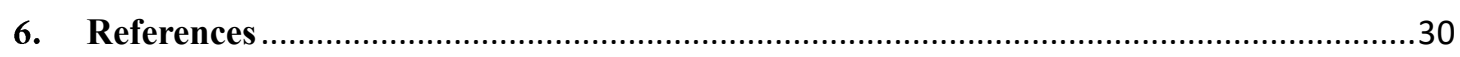




\section{Supplementary Spectra and Graphs and other Data}

Scheme S1. Rational design and convergent synthesis of PDE10A catalytic-site targeting fluorescence probes BVQ1812-1815.

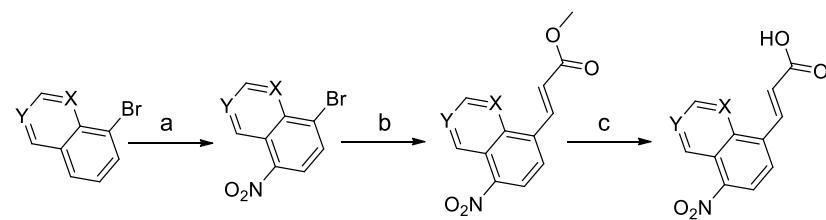

1a: $X=N, Y=C$; 1b: $X=C, Y=N$;

2a: $X=N, Y=C ;$

3a: $X=N, Y=C$;

3b: $X=C, Y=N$
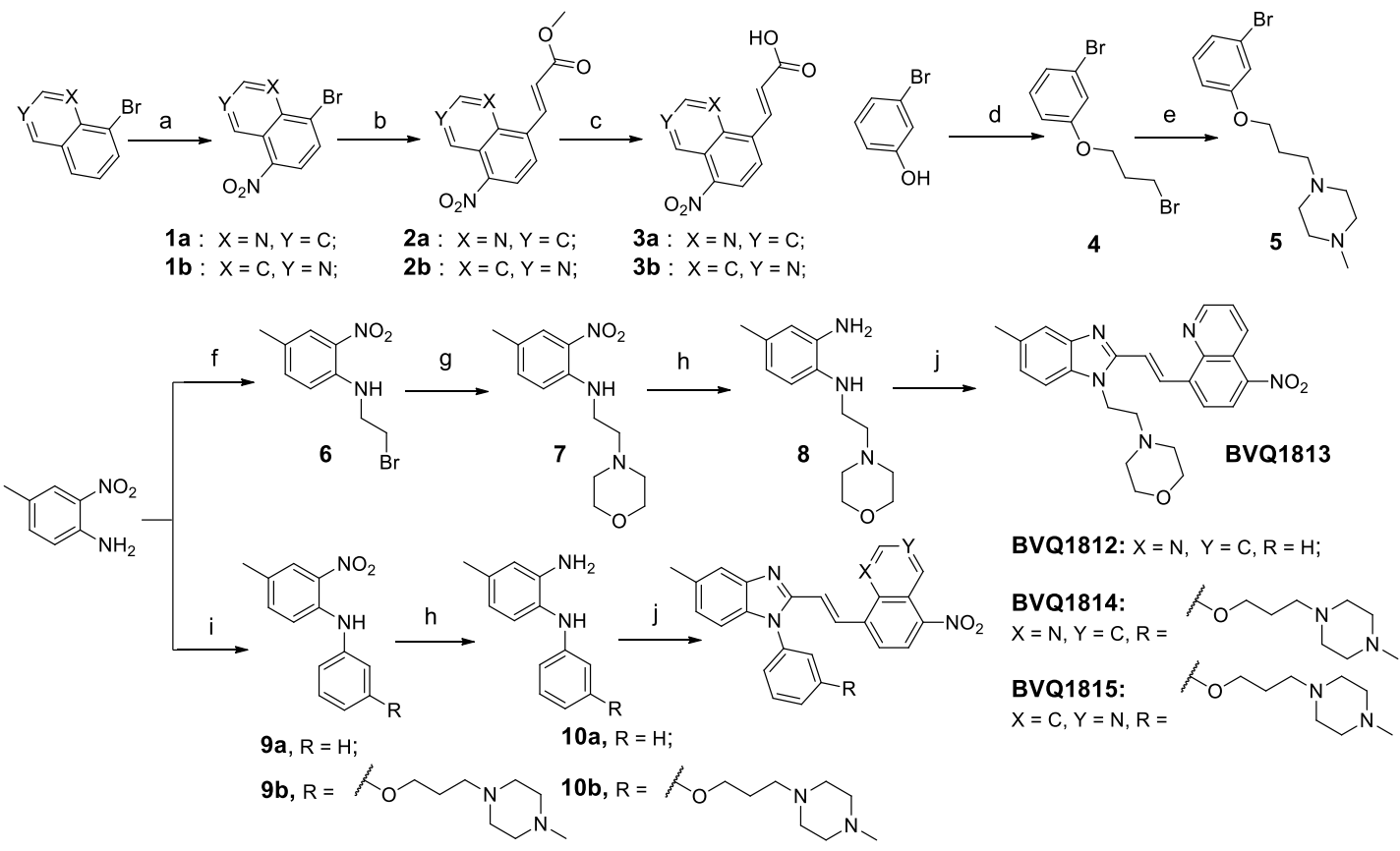

Reagents and conditions: (a) $\mathrm{HNO}_{3}$, con. $\mathrm{H}_{2} \mathrm{SO}_{4}, 0{ }^{\circ} \mathrm{C}$, overnight; (b) methyl acrylate, $\mathrm{Pd}(\mathrm{OAc})_{2}, \mathrm{CH}_{3} \mathrm{COOK}, N$ methyl pyrrolidone (NMP), $135{ }^{\circ} \mathrm{C}, 2 \mathrm{~h}$; (c) $6 \mathrm{M} \mathrm{NaOH}$, MeOH, RT, overnight; (d) 1,3-dibromopropane, $\mathrm{K}_{2} \mathrm{CO}_{3}$, DMF, RT, 2 h; (e) 1-methylpiperazine, $\mathrm{K}_{2} \mathrm{CO}_{3}, \mathrm{CH}_{3} \mathrm{CN}, 80{ }^{\circ} \mathrm{C}, 6 \mathrm{~h}$; (f) 1,2-dibromoethane, $N, N$-Diisopropyl ethylamine (DIPEA), 4-dimethylaminopyridine (4-DMAP), $120{ }^{\circ} \mathrm{C}, 24 \mathrm{~h}$; (g) morpholine, $\mathrm{K}_{2} \mathrm{CO}_{3}, \mathrm{CH}_{3} \mathrm{CN}, 80{ }^{\circ} \mathrm{C}$, 6h; (h) Pd/C, $\mathrm{H}_{2}$, EtOH, RT, overnight; (i) 5 (or bromobenzene), $\mathrm{Pd}_{2}(\mathrm{dba})_{3},( \pm)-2,2$ '-Bis(diphenylphosphino)-1,1'binaphthalene (BINAP), $\mathrm{Cs}_{2} \mathrm{CO}_{3}$, toluene, $110{ }^{\circ} \mathrm{C}$, overnight; (j) i) 3a (or 3b), 2-(7-Azabenzotriazol-1-yl)-N,N,N',N'tetramethyluronium hexafluorophosphate (HATU), DIPEA, $\mathrm{CH}_{2} \mathrm{Cl}_{2}$, overnight; ii) $\mathrm{AcOH}, 90{ }^{\circ} \mathrm{C}$, overnight.

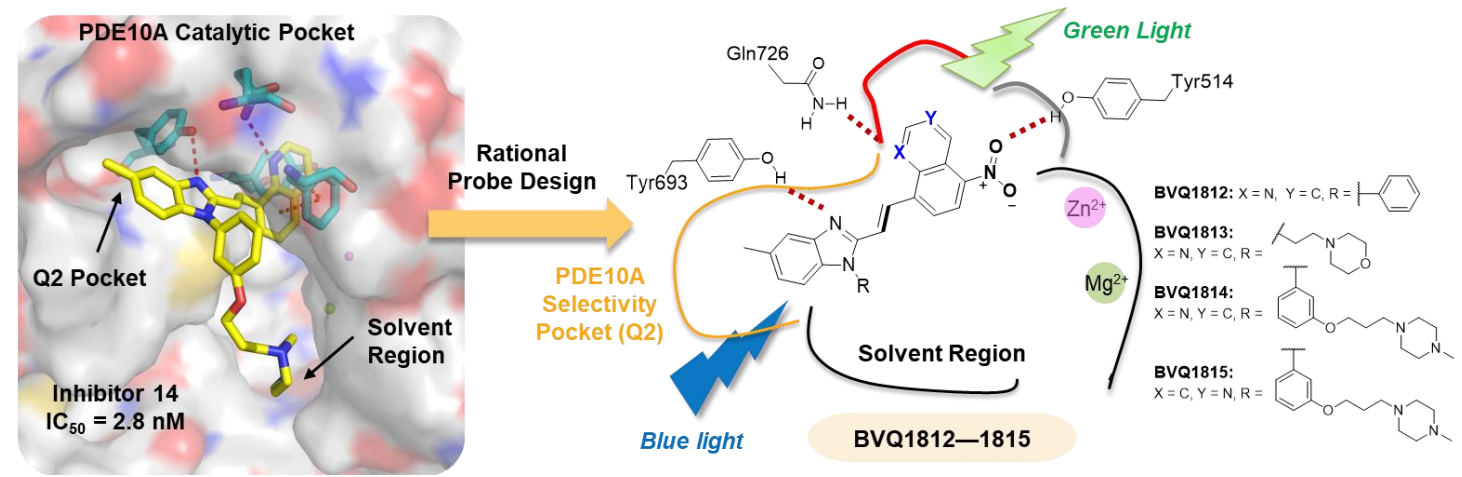

Figure S1. Rational design strategy of PDE10A catalytic-site targeting fluorescence probes. 


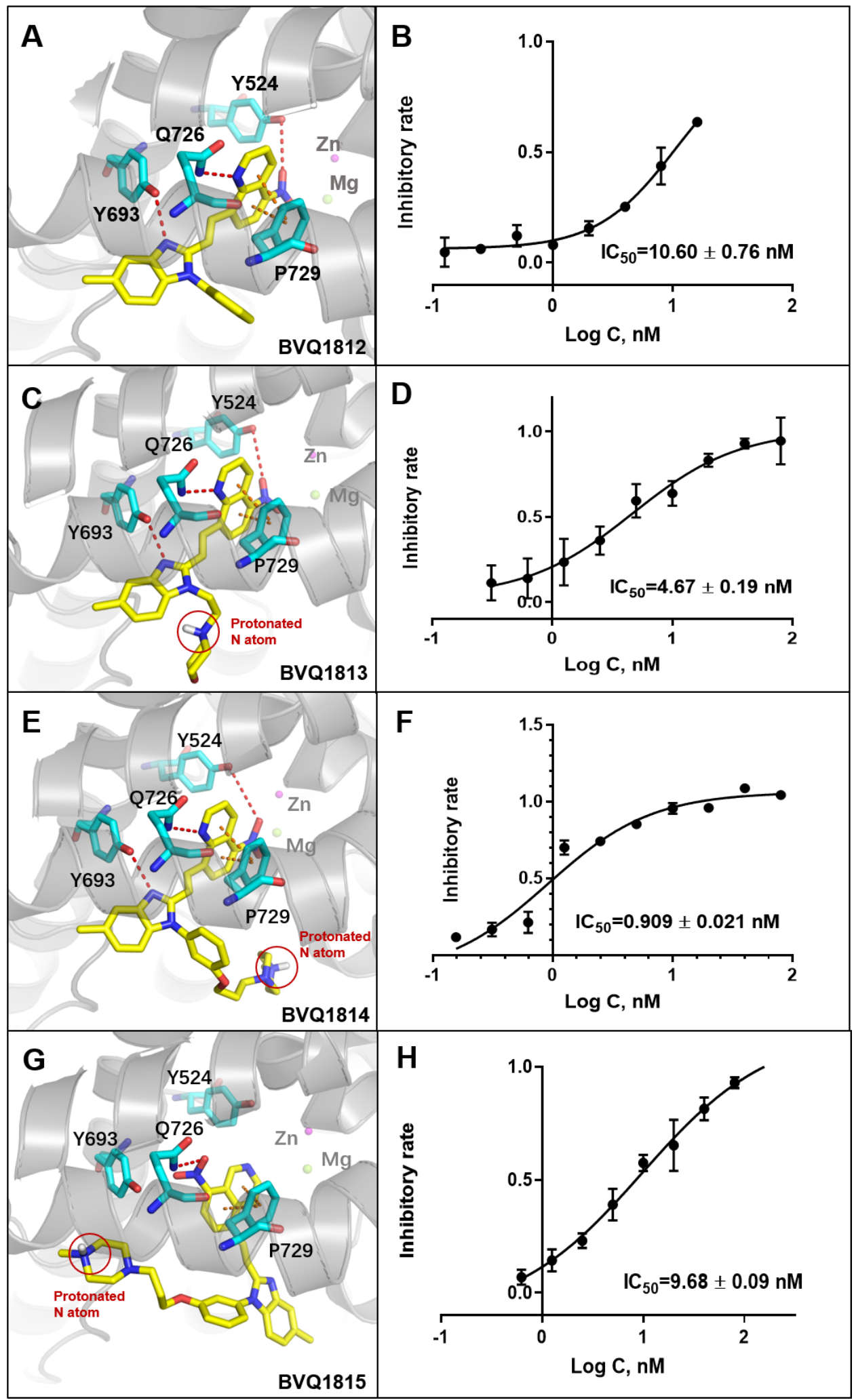

Figure S2. (A) The diagram of molecular docking between probes and PDE10A protein. The protonation states of the ligands are predicted by the Ligand Preparation module in the Tripos Sybyl 2.0. (B) The inhibitory activity result of BVQ1814 toward PDE10A. Values of PDE10A inhibitory rate are presented as the means $\pm \mathrm{SD}(\mathrm{n}=3)$ with papaverine as a positive control $\left(\mathrm{IC}_{50}=0.1 \mu \mathrm{M}\right){ }^{1}$ 
Table S1. MM-GBSA method and $\mathrm{IC}_{50}$ values for fluorescent probes

\begin{tabular}{|c|c|c|c|c|c|}
\hline & Inhibitor 14 & BVQ1812 & BVQ1813 & BVQ1814 & BVQ1815 \\
\hline $\begin{array}{l}\text { MM-GBSA } \\
\text { (kcal / mol) }\end{array}$ & $-38.10 \pm 3.87$ & $-40.72 \pm 2.66$ & $-37.69 \pm 2.48$ & $-47.35 \pm 3.48$ & $-46.21 \pm 3.36$ \\
\hline $\mathrm{IC}_{50}(\mathrm{nM})$ & 2.8 & 10.6 & 4.67 & 0.91 & 9.68 \\
\hline
\end{tabular}

Binding free energies of probes or PDE10A inhibitor 14 binding towards PDE10A estimated by MMGBSA method according to the crystal structure of PDE10A inhibitor 14 and the PDE10A recombinant protein.

Table S2. $\mathrm{IC}_{50}$ and selectivity assessment of BVQ1814 and TAK-063 ${ }^{2}$

\begin{tabular}{|c|c|c|c|c|}
\hline & \multicolumn{2}{|c|}{ BVQ1814 } & \multicolumn{2}{|c|}{ TAK063 $^{c}$} \\
\hline PDEs & $\mathrm{IC}_{50}{ }^{\mathrm{a}}$ & Selectivity ${ }^{b}$ & $\mathrm{IC}_{50}{ }^{\mathrm{b}}$ & Selectivity ${ }^{b}$ \\
\hline PDE1 & $>10 \mu \mathrm{M}$ & $>10000$ & $12.0 \pm 2.2 \mu \mathrm{M}$ & 40000 \\
\hline PDE2 & $1.30 \pm 0.06 \mu \mathrm{M}$ & 1428 & $>30 \mu \mathrm{M}$ & $>100000$ \\
\hline PDE3 & $2.21 \pm 0.05 \mu \mathrm{M}$ & 2428 & $>30 \mu \mathrm{M}$ & $>100000$ \\
\hline PDE4 & $1.96 \pm 0.12 \mu \mathrm{M}$ & 2154 & $5.5 \pm 0.5 \mu \mathrm{M}$ & 18333 \\
\hline PDE5 & $>10 \mu \mathrm{M}$ & $>10000$ & $5.7 \pm 1.0 \mu \mathrm{M}$ & 19000 \\
\hline PDE7 & $1.71 \pm 0.08 \mu \mathrm{M}$ & 1879 & $19.0 \pm 1.0 \mu \mathrm{M}$ & 63333 \\
\hline PDE8 & $0.99 \pm 0.01 \mu \mathrm{M}$ & 1088 & $>30 \mu \mathrm{M}$ & $>100000$ \\
\hline PDE9 & $>10 \mu \mathrm{M}$ & $>10000$ & $>30 \mu \mathrm{M}$ & $>100000$ \\
\hline PDE10 & $0.91 \pm 0.02 \mathrm{nM}$ & - & $0.3 \pm 0.08 \mathrm{nM}$ & - \\
\hline
\end{tabular}

${ }^{\text {a }}$ Values of PDE10A inhibitory rate are presented as the means $\pm \operatorname{SD}(\mathrm{n}=3)$ with papaverine as a positive control $\left(\mathrm{IC}_{50}=0.1 \mu \mathrm{M}\right) .{ }^{\mathrm{b}}$ Selectivity $=\mathrm{IC}_{50(\mathrm{PDEs})} / \mathrm{IC}_{50(\mathrm{PDE} 10 \mathrm{~A})}{ }^{\mathrm{c}} \mathrm{IC}_{50}$ results from ref. $2 .{ }^{2}$ 

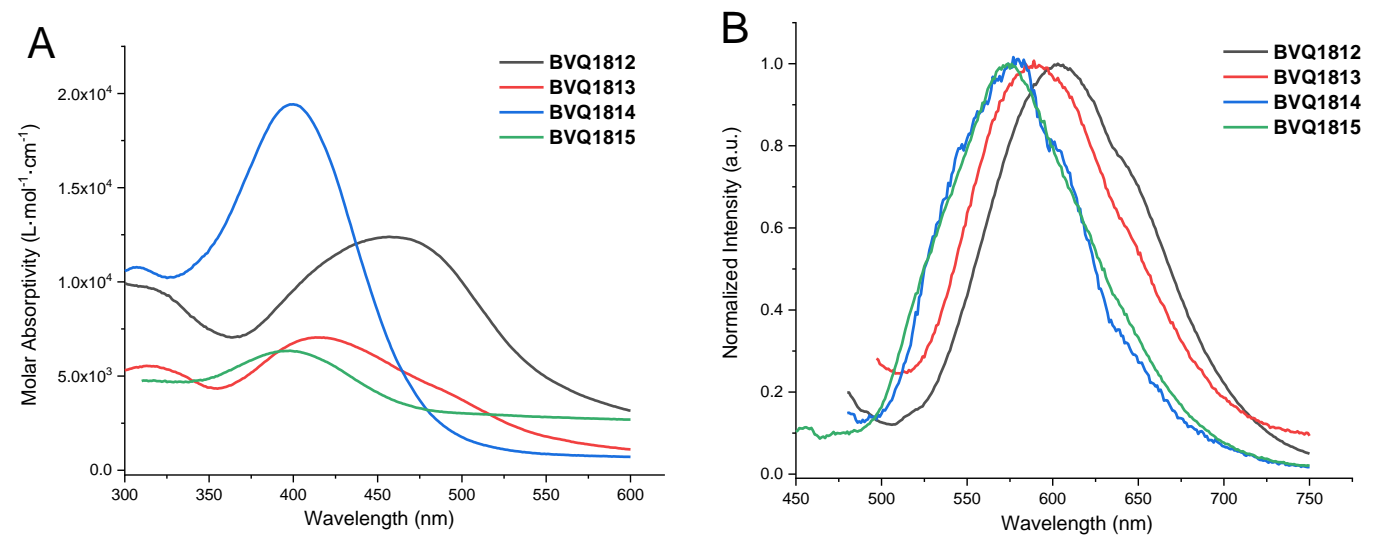

Figure S3. Absorption and fluorescence spectra of BVQ1812-1815 in $\mathrm{H}_{2} \mathrm{O}$.

Table S3. Summary of properties of BVQ1812-1815 in $\mathrm{H}_{2} \mathrm{O}$

\begin{tabular}{|c|c|c|c|c|}
\hline & BVQ1812 & BVQ1813 & BVQ1814 & BVQ1815 \\
\hline $\boldsymbol{\varepsilon}\left(\mathbf{L} \cdot \mathbf{m o l}^{-\mathbf{1}} \cdot \mathbf{c m}^{-\mathbf{1}}\right)$ & 12393 & 3524 & 19422 & 6348 \\
\hline$\lambda_{\mathrm{ab}} \mathbf{( n m )}$ & 457 & 413 & 398 & 398 \\
\hline$\lambda_{\mathrm{em}} \mathbf{( n m )}$ & 603 & 589 & 578 & 574 \\
\hline $\boldsymbol{\Phi}(\mathbf{\%})$ & 20.6 & 5.2 & 12.3 & 11.2 \\
\hline
\end{tabular}

$\varepsilon$ : Molar absorptivity; $\lambda_{\mathrm{ab}}$ : The maximum of the absorption peak; $\lambda_{\mathrm{em}}$ : The maximum of the emission peak; $\Phi$ : Relative Fluorescence quantum yield using Fluorescein $\left(\Phi_{470}=0.91\right)$ as a standard.
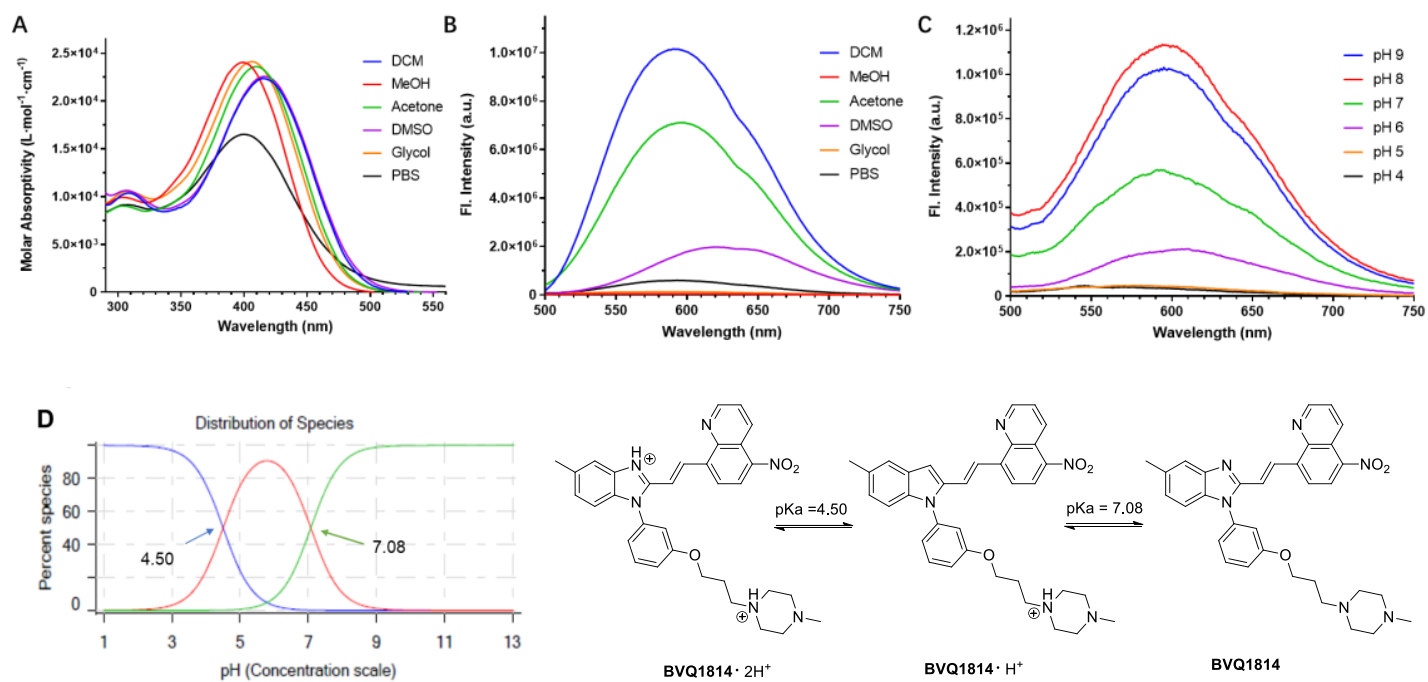

Figure S4. (A) Absorption spectra of BVQ1814 in different solvents. (B) Fluorescence spectra of BVQ1814 in different solvent. (C) Fluorescence spectra of BVQ1814 in Tris-HCl buffer at different $\mathrm{pH}$ values. (D) The pKa values of the protonated forms of BVQ1814 were 7.08 and 4.50, respectively. DCM means dichloromethane. 


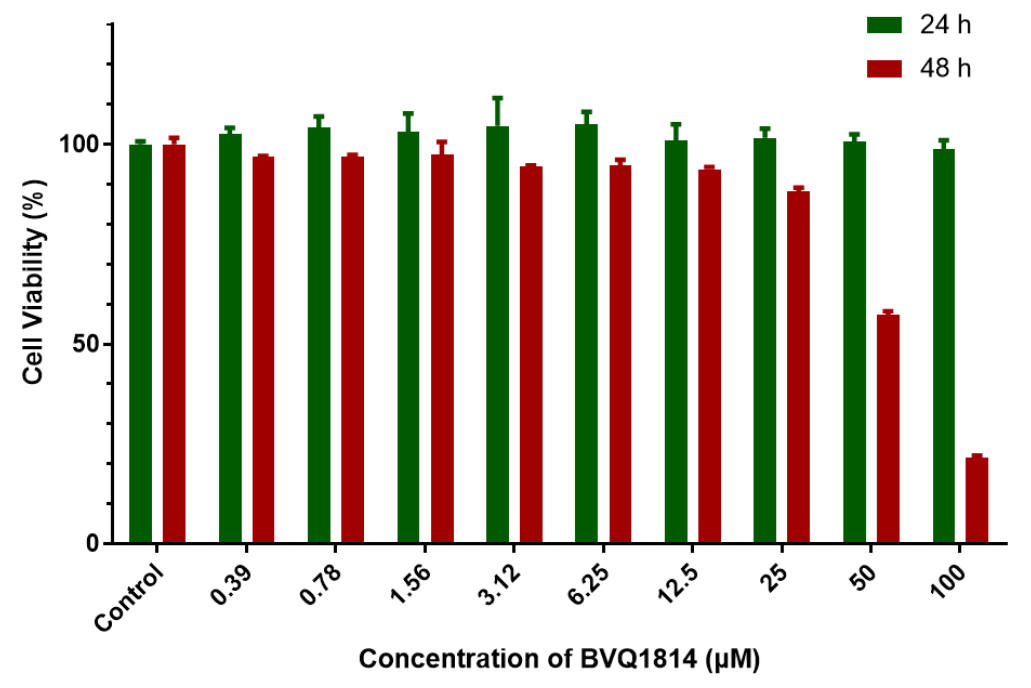

Figure S5. Cytotoxicity test of BVQ1814 in Hela cells after a 24 h- or 48 h-incubation.

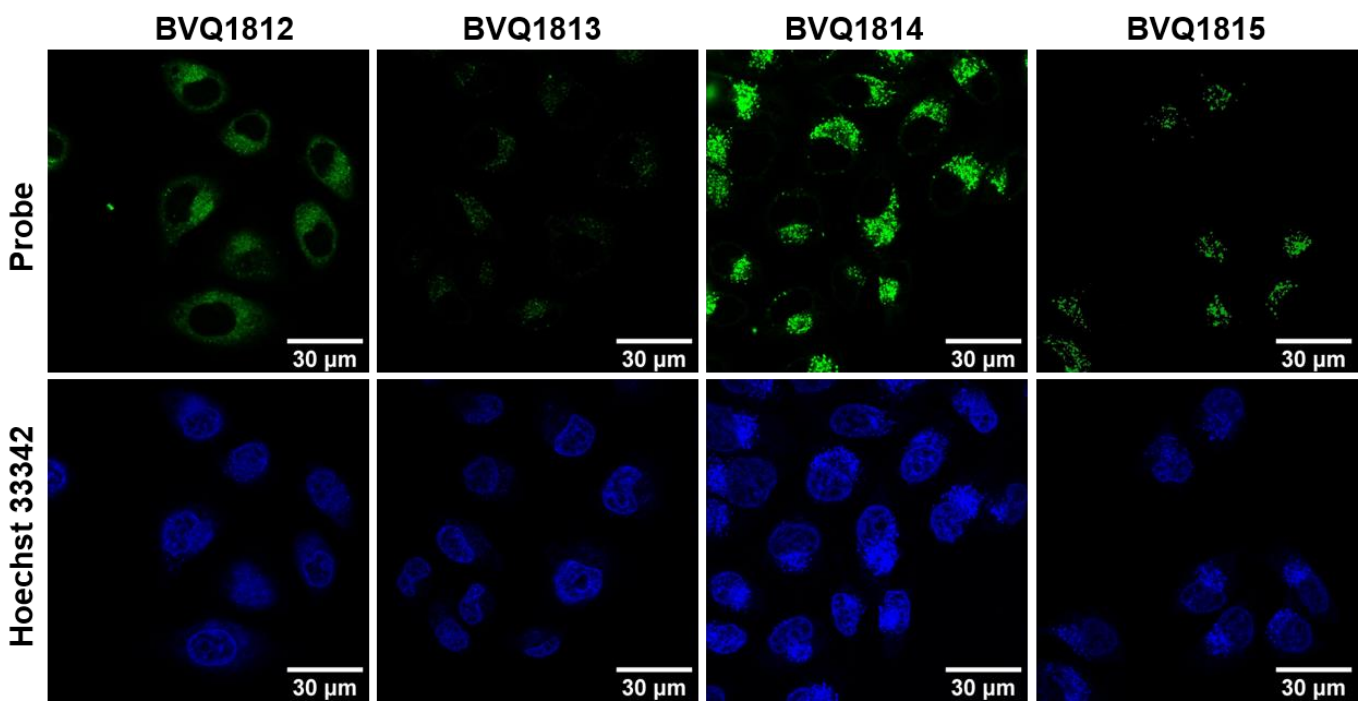

Figure S6. Fluorescent cell imaging co-stained with probes and Hoechst 33342 in living cells. 


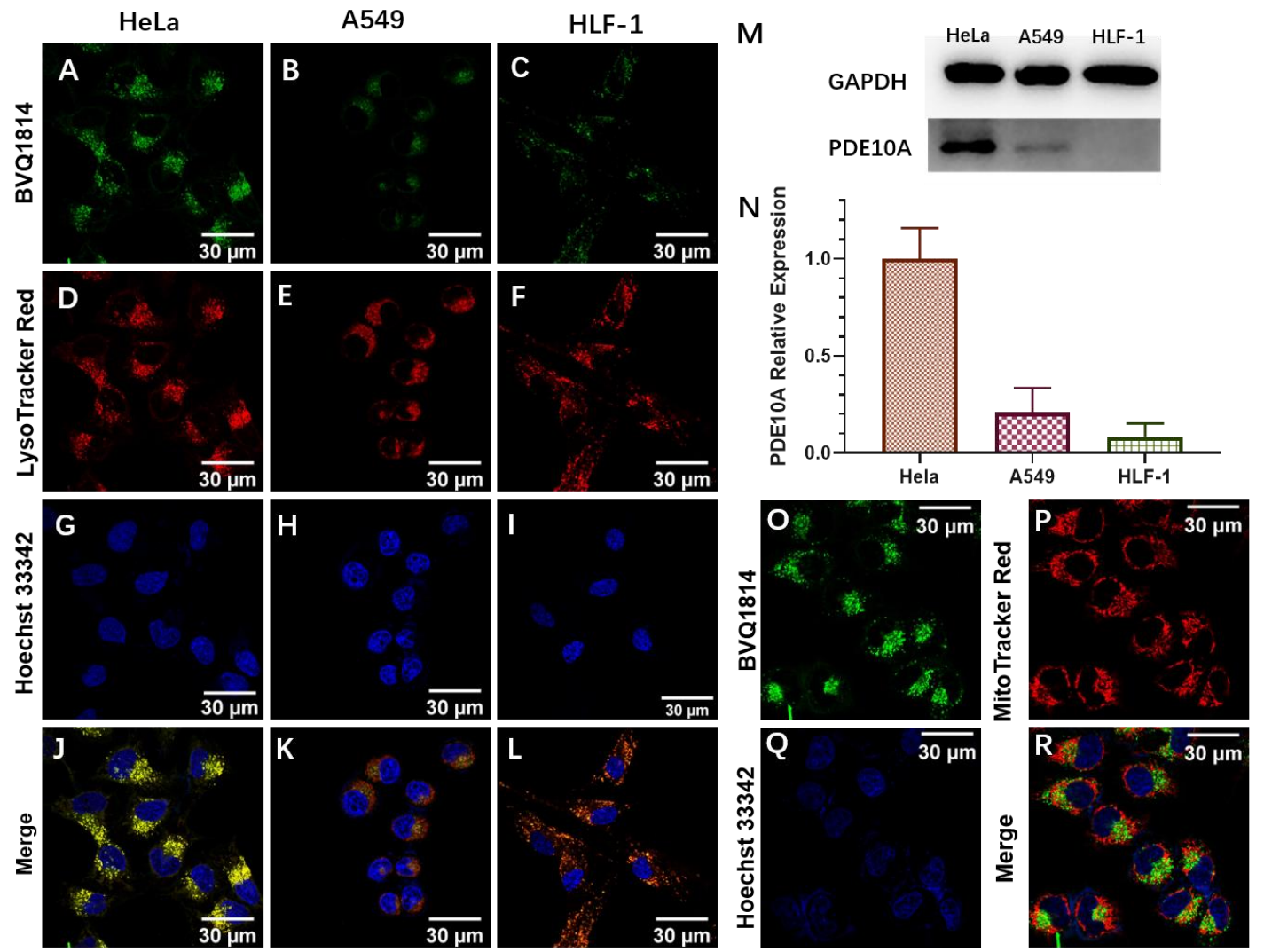

Figure S7. (A-L) Fluorescent cell imaging co-stained with BVQ1814, Lysotracker Red and Hoechst 33342 by a confocal fluorescence microscope at the same condition. $(\mathrm{M}-\mathrm{N})$ The changes of PDE10A expression in different cells analyzed with Western Blot method. $(\mathrm{O}-\mathrm{R})$ Fluorescent cell imaging costained with BVQ1814, MitoLite Deep Red and Hoechst 33342, respectively.

Table S4 Fluorescent dyes for cell staining

\begin{tabular}{|l|l|l|l|}
\hline Fluorescent Dye & Supplier & Cat \# & Specification \\
\hline Hoechst 33342 & Beyotime & C1029 & $100 \mathrm{X}$ \\
\hline DAPI & Solarbio & C00065 & $1 \mathrm{X}$ \\
\hline LysoTracker Red & Beyotime & $\mathrm{C} 1046$ & $20000 \mathrm{X}$ \\
\hline MitoLite Deep Red & AAT Bioquest & 22678 & $500 \mathrm{X}$ \\
\hline
\end{tabular}

Table S5 Primers in quantitative Real-time PCR (qRT-PCR) assays

\begin{tabular}{|l|l|l|l|}
\hline Species & Gene & Forward (5' to $\mathbf{3}^{\prime}$ ) & Reverse (5' to $\left.\mathbf{3}^{\prime}\right)$ \\
\hline Rat & PDE10A & GACTTGATTGGCATCCTTGAA & CCTGGTGTATTGCTACGGAAG \\
\hline Rat & PBGD & CAAGGTTTTCAGCATCGCTAC & ATGTCCGGTAACGGCGGC \\
\hline human & PDE10A & AACTATCGGCGGGTTCCTTATC & GCGTGTGATTGTTCTGAAGTATGG \\
\hline human & GAPDH & TTGACTCCGACCTTCACCTTC & CGCTCTCTGCTCCTCCTGTTC \\
\hline
\end{tabular}




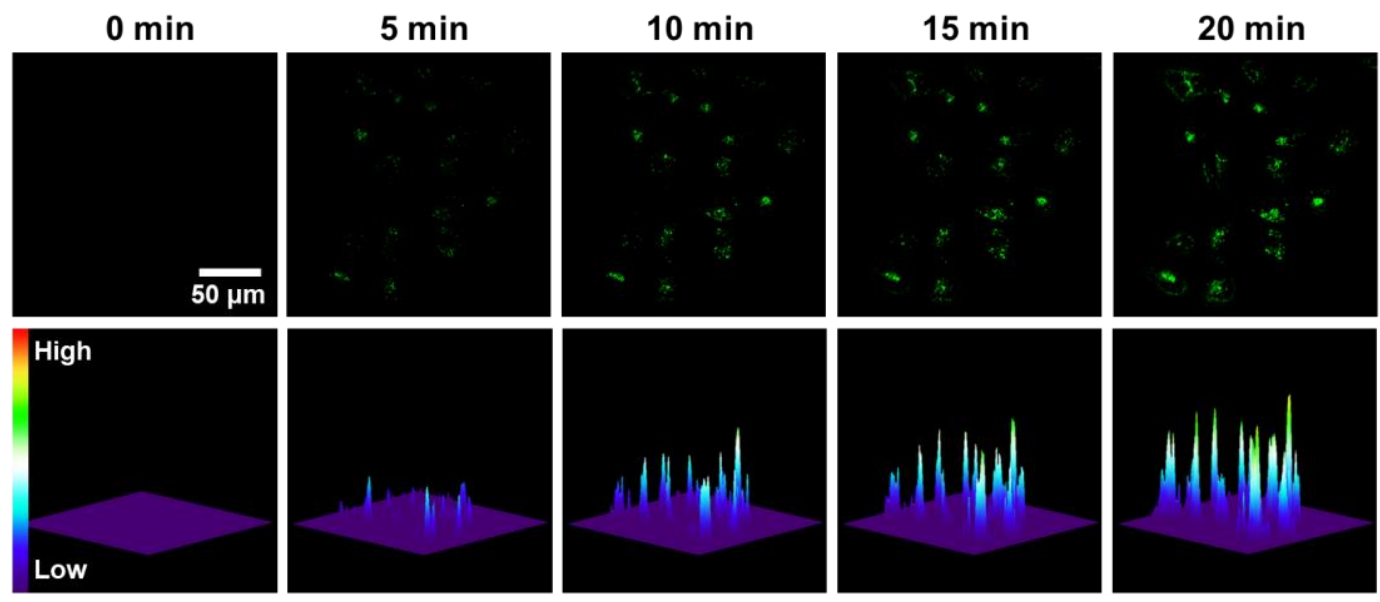

Figure S8. The changes of fluorescent intensity of BVQ1814 over time in live HeLa cells.

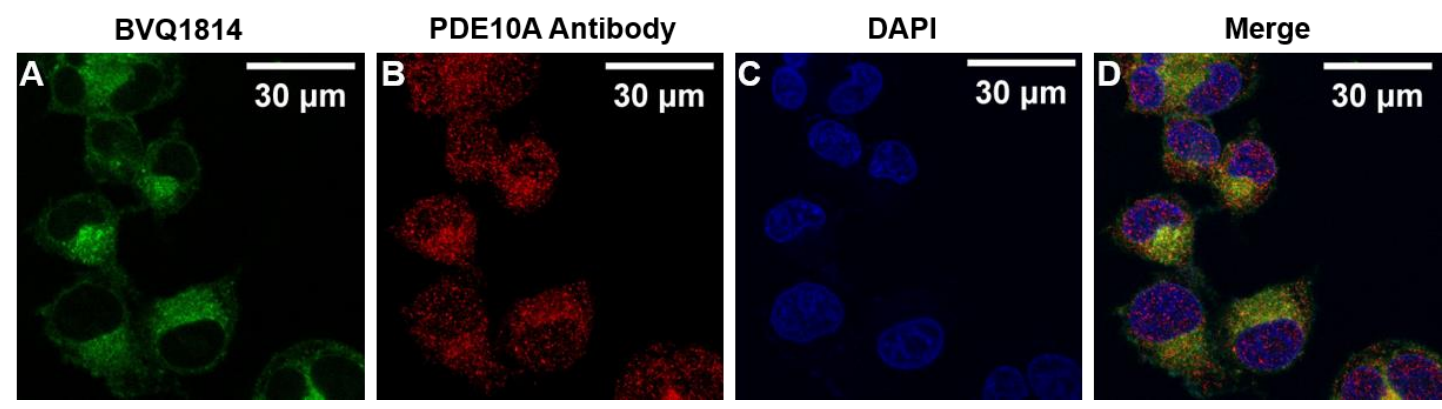

Figure S9. Immunofluorescence staining of PDE10A in fixed HeLa cells: (A) BVQ1814, (B) PDE10A, (C) DAPI and (D) Overlay fluorescent images.
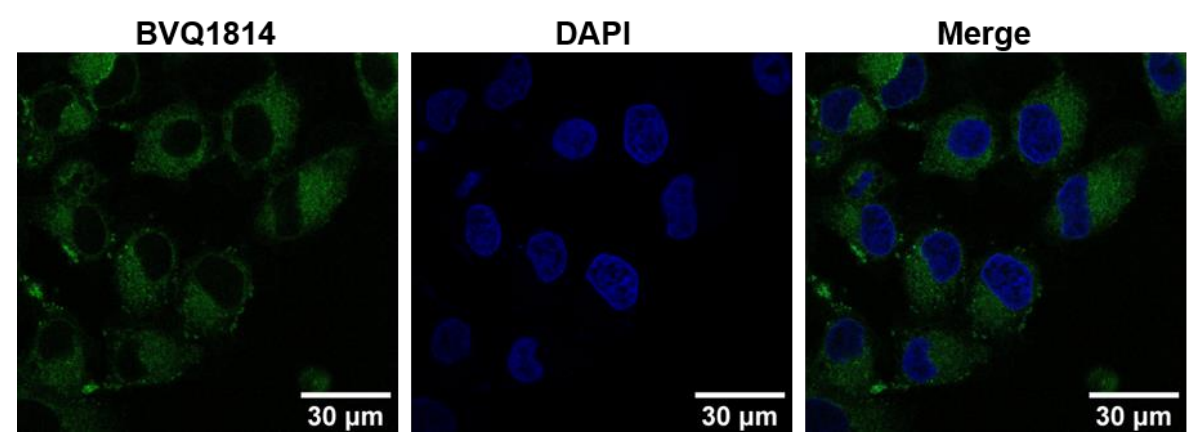

Figure S10. Fixed Hela cells stained by BVQ1814 and DAPI, respectively. BVQ1814 could hardly enter the nucleus region of fixed cells. 


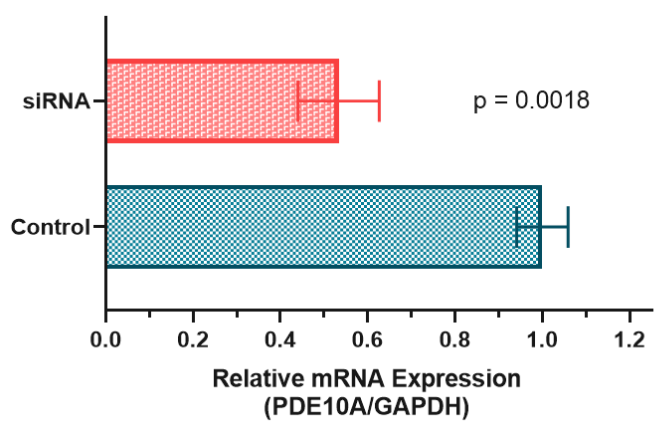

Figure S11. Interference effect of PDE10A siRNA

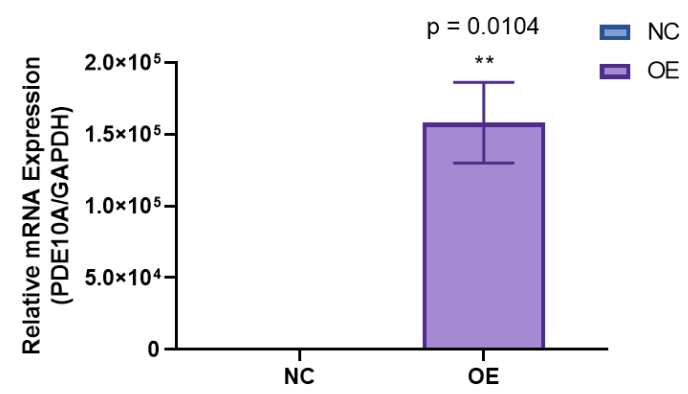

Figure S12. PDE10A mRNA expression assays by qRT-PCR method. Remarkable increasement of PDE10A mRNA levels in the stable mcherry-PDE10A overexpressing HepG2 cells transfected by lentiviral vectors. OE means the mcherry-PDE10A overexpressing group, $\mathrm{NC}$ means the normal control group.
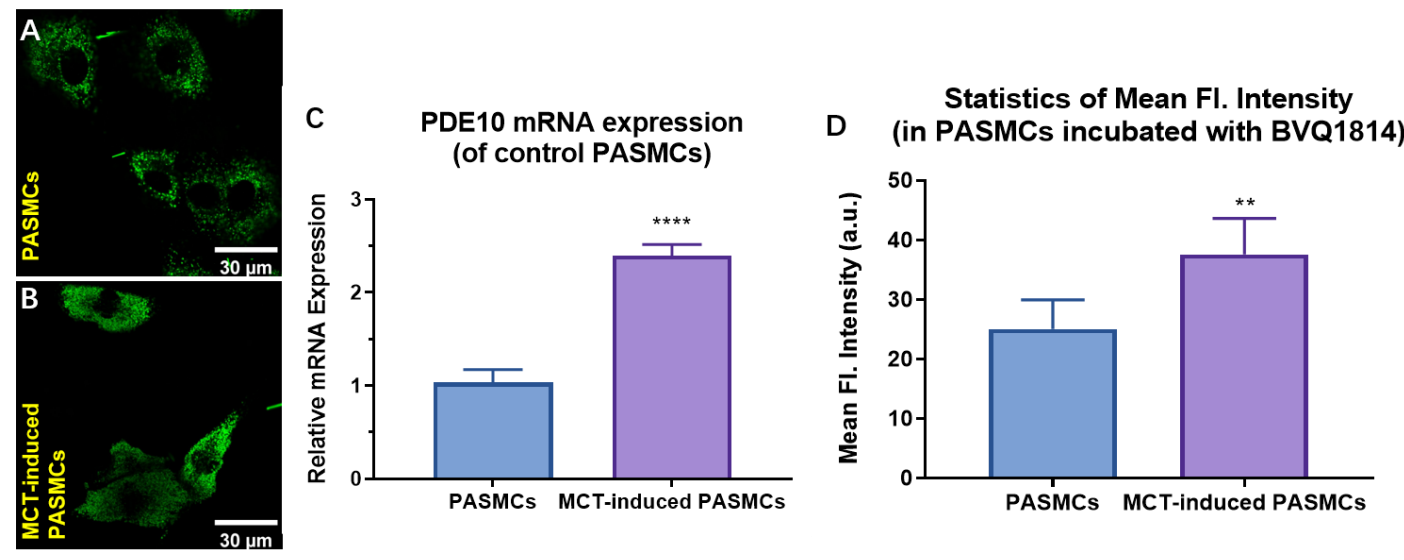

Figure S13. (A-B) fluorescence images of BVQ1814 in primary rat pulmonary artery smooth muscle cells (rPASMCs) and MCT-PAH rPASMCs, respectively. (C) The PDE10A mRNA expression levels in rPASMCs, $\left(^{* * * *}\right) P<0.0001$. (D) Mean fluorescence intensity in rPASMCs incubated with BVQ1814, $\left({ }^{* *}\right)$ $P<0.01$. Images were analyzed by imageJ software. 


\section{Materials and instruments}

All reagents and solvents are commercially available and used as received unless otherwise noted. Water used for the fluorescence and biological studies was doubly distilled and further purified with a Mill-Q filtration system. ${ }^{1} \mathrm{H}$ NMR and ${ }^{13} \mathrm{C}$ NMR were recorded on a BrukerBioSpin GmbH spectrometer (AvanceIII, Bruker) at a $400 \mathrm{MHz}$ NMR and $126 \mathrm{MHz}$ NMR, respectively, and the chemical shifts of $\mathrm{CDCl}_{3}$ in NMR spectra were corrected as $\delta 7.26 \mathrm{ppm}$ for ${ }^{1} \mathrm{H} \mathrm{NMR}$ and $\delta 77.16 \mathrm{ppm}$ for ${ }^{13} \mathrm{C}$ NMR, respectively. Mass spectra were performed by a LC-MS spectrometer (LCMS-2020, Shimadzu). Absorption spectra were measured by UV/VIS spectrometer SHIMADZU UV-2600 and fluorescence spectra were obtained under the fluorescence spectrograph HORIBA Fluoromax-4. The CCK-8 cytotoxicity assay was conducted on a microplatereader (POLARstar, Omega). Fluorescence imaging was performed by using the fluorescence microscopy (DMI-3000B, OLYMPUS) and the confocal fluorescence microscopy (FV-3000, OLYMPUS). Quantitative Real-time PCR (qRT-PCR) assays were performed by using QPCR system (lightCycler480II, Roche).

\section{Synthesis of probes BVQ1812-1815}

8-Bromo-5-nitroquinoline (1a). 8-Bromoquinoline $(2.0 \mathrm{~g}, 9.7 \mathrm{mmol})$ was slowly added to a mixture of Con. $\mathrm{H}_{2} \mathrm{SO}_{4}(6 \mathrm{~mL}, 98 \%)$ and $\mathrm{KNO}_{3}(4.2 \mathrm{~g}, 38.8 \mathrm{mmol})$ at $0{ }^{\circ} \mathrm{C}$. The reaction mixture was allowed to warm to room temperature at which it was stirred for $2 \mathrm{~h}$. The mixture was basified with a saturated solution of $\mathrm{Na}_{2} \mathrm{CO}_{3}$ to $\mathrm{pH}=9$ and extracted with ethyl acetate $(3 \times 20 \mathrm{~mL})$. The combined organic layers were dried over anhydrous $\mathrm{Na}_{2} \mathrm{SO}_{4}$, filtered and evaporated under reduced pressure to obtain $1.42 \mathrm{~g}$ of pure product $1 \mathrm{a}$ in $58 \%$ yield. ${ }^{1} \mathrm{H} \mathrm{NMR}\left(400 \mathrm{MHz}, \mathrm{CDCl}_{3}\right) \delta 9.16(\mathrm{dd}, J=4.1,1.5 \mathrm{~Hz}, 1 \mathrm{H}), 9.06(\mathrm{dd}, J$ $=8.8,1.5 \mathrm{~Hz}, 1 \mathrm{H}), 8.22(\mathrm{dd}, J=21.2,8.3 \mathrm{~Hz}, 2 \mathrm{H}), 7.73(\mathrm{dd}, J=8.8,4.1 \mathrm{~Hz}, 1 \mathrm{H}) . \mathrm{MS}(\mathrm{ESI}) \mathrm{m} / \mathrm{z}[\mathrm{M}+$ $\mathrm{H}]^{+} 253.05$.

Methyl (E)-3-(5-nitroquinolin-8-yl)acrylate (2a) . To the solution of 1a (8.95 g, $35.4 \mathrm{mmol})$ in NMP $(27 \mathrm{~mL})$ was added methyl acrylate $(3.6 \mathrm{~g}, 42.5 \mathrm{mmol}), \mathrm{CH}_{3} \mathrm{COOK}(6.86 \mathrm{~g}, 70 \mathrm{mmol})$ and $\mathrm{Pd}(\mathrm{OAc})_{2}$ (794 mg, $3.54 \mathrm{mmol}$ ) in sequence, then the mixture was heated to $120{ }^{\circ} \mathrm{C}$ stirring overnight under argon atmosphere. After cooling to room temperature, the solid was filtered through sufficient Celite, and then poured into water and extracted with EA $(200 \times 3 \mathrm{~mL})$, then the organic phase was washed with water $(50 \times 3 \mathrm{~mL})$, brine $(50 \times 3 \mathrm{~mL})$, and dried over anhydrous sodium sulfate. After concentration in vacuo the residue was purified by silica gel column chromatography (DCM/MeOH, 100:1) to afford a product $4.41 \mathrm{~g}$ in $48 \%$ yield. ${ }^{1} \mathrm{H}$ NMR $\left(400 \mathrm{MHz}, \mathrm{CDCl}_{3}\right) \delta 10.04(\mathrm{~d}, J=0.5 \mathrm{~Hz}, 1 \mathrm{H}), 8.82(\mathrm{~d}, J=6.0 \mathrm{~Hz}, 1 \mathrm{H})$, $8.40(\mathrm{~d}, J=15.8 \mathrm{~Hz}, 1 \mathrm{H}), 8.33(\mathrm{~d}, J=8.0 \mathrm{~Hz}, 1 \mathrm{H}), 8.08-8.03(\mathrm{~m}, 1 \mathrm{H}), 8.00(\mathrm{~d}, J=8.0 \mathrm{~Hz}, 1 \mathrm{H}), 6.65$ $(\mathrm{d}, J=15.8 \mathrm{~Hz}, 1 \mathrm{H}), 3.91(\mathrm{~s}, 3 \mathrm{H}) . \mathrm{MS}(\mathrm{ESI}) \mathrm{m} / \mathrm{z}[\mathrm{M}+\mathrm{H}]^{+} 259.20$.

Methyl (E)-3-(8-nitroisoquinolin-5-yl)acrylate (2b). $550 \mathrm{mg}$, yield 45\%. $\left.{ }^{1} \mathrm{H} \mathrm{NMR} \mathrm{(400} \mathrm{MHz,} \mathrm{CDCl}_{3}\right)$ $\delta 10.04(\mathrm{~s}, 1 \mathrm{H}), 8.82(\mathrm{~d}, J=6.0 \mathrm{~Hz}, 1 \mathrm{H}), 8.40(\mathrm{~d}, J=15.8 \mathrm{~Hz}, 1 \mathrm{H}), 8.33(\mathrm{~d}, J=8.0 \mathrm{~Hz}, 1 \mathrm{H}), 8.06(\mathrm{~d}, J$ $=5.4 \mathrm{~Hz}, 1 \mathrm{H}), 8.00(\mathrm{~d}, J=8.0 \mathrm{~Hz}, 1 \mathrm{H}), 7.28(\mathrm{~s}, 1 \mathrm{H}), 6.65(\mathrm{~d}, J=15.8 \mathrm{~Hz}, 1 \mathrm{H}), 3.91(\mathrm{~s}, 3 \mathrm{H})$. MS (ESI) 
$\mathrm{m} / \mathrm{z}[\mathrm{M}+\mathrm{H}]^{+} 259.20$

(E)-3-(5-nitroquinolin-8-yl)acrylic acid (3a) . To the solution of 2a (2.0 g, $7.75 \mathrm{mmol})$ in EtOH (30 $\mathrm{mL})$ was added $6 \mathrm{M} \mathrm{NaOH}(5 \mathrm{~mL})$, and the mixture was stirred at room temperature overnight. After completion of the reaction, solvent was removed in vacuo, and then the solution was acidified with $1 \mathrm{M}$ aqueous $\mathrm{HCl}$ to $\mathrm{pH}=1-2$. The yellow solid was filtered to afford a product $(1.5 \mathrm{~g})$. Yield, $80 \%{ }^{1} \mathrm{H} \mathrm{NMR}$ $\left(400 \mathrm{MHz}, \mathrm{DMSO}-d_{6}\right) \delta 9.78(\mathrm{~s}, 1 \mathrm{H}), 8.77(\mathrm{~d}, J=6.0 \mathrm{~Hz}, 1 \mathrm{H}), 8.43(\mathrm{~d}, J=8.2 \mathrm{~Hz}, 1 \mathrm{H}), 8.33(\mathrm{~s}, 1 \mathrm{H})$, $8.30(\mathrm{~d}, J=8.0 \mathrm{~Hz}, 1 \mathrm{H}), 8.24(\mathrm{~d}, J=6.0 \mathrm{~Hz}, 1 \mathrm{H}), 6.78(\mathrm{~d}, J=15.8 \mathrm{~Hz}, 1 \mathrm{H}) . \mathrm{MS}(\mathrm{ESI}) \mathrm{m} / \mathrm{z}[\mathrm{M}+\mathrm{H}]^{+}$ 245.15 .

(E)-3-(8-nitroisoquinolin-5-yl)acrylic acid (3b). $476 \mathrm{mg}$, Yield, 80\%. ${ }^{1} \mathrm{H}$ NMR (400 MHz, DMSO) $\delta$ $9.78(\mathrm{~s}, 1 \mathrm{H}), 8.77(\mathrm{~d}, J=6.0 \mathrm{~Hz}, 1 \mathrm{H}), 8.43(\mathrm{~d}, J=8.2 \mathrm{~Hz}, 1 \mathrm{H}), 8.33(\mathrm{~s}, 1 \mathrm{H}), 8.30(\mathrm{~d}, J=8.0 \mathrm{~Hz}, 1 \mathrm{H})$, $8.24(\mathrm{~d}, J=6.0 \mathrm{~Hz}, 1 \mathrm{H}), 6.78(\mathrm{~d}, J=15.8 \mathrm{~Hz}, 1 \mathrm{H}) . \mathrm{MS}(\mathrm{ESI}) \mathrm{m} / \mathrm{z}[\mathrm{M}+\mathrm{H}]^{+} 245.16$

1-Bromo-3-(3-bromopropoxy)benzene (4). The solution of 3-bromophenol (4.32 g, $25 \mathrm{mmol})$ in DMF $(10 \mathrm{~mL})$ was added dropwise into the solution of 1,3-dibromopropane (10.08 g, $50 \mathrm{mmol})$ and $\mathrm{K}_{2} \mathrm{CO}_{3}$ (5.18 g, $37.5 \mathrm{mmol})$ in DMF $(25 \mathrm{~mL})$, The mixture was stirred for $2 \mathrm{~h}$ at room temperature, then stirred for another $2 \mathrm{~h}$ at $70{ }^{\circ} \mathrm{C}$. After completion of the reaction, the mixture was poured into water and extracted with EA $(100 \times 3 \mathrm{~mL})$, then the organic phase was combined and washed with water $(25 \times 3 \mathrm{~mL})$, brine $(25 \times 3 \mathrm{~mL})$, and dried over anhydrous sodium sulfate. After concentration in vacuo the residue was purified by silica gel column chromatography (PE/EA, 10:1) to afford a product (6.0 g). Yield, 77\%; ${ }^{1} \mathrm{H}$ $\operatorname{NMR}\left(400 \mathrm{MHz}, \mathrm{CDCl}_{3}\right) \delta 7.14(\mathrm{dd}, J=10.1,6.4 \mathrm{~Hz}, 1 \mathrm{H}), 7.10-7.06(\mathrm{~m}, 2 \mathrm{H}), 6.84(\mathrm{~d}, J=8.2 \mathrm{~Hz}, 1 \mathrm{H})$, $4.01(\mathrm{t}, J=6.3 \mathrm{~Hz}, 2 \mathrm{H}), 2.53(\mathrm{t}, 2 \mathrm{H}), 2.00-1.96(\mathrm{~m}, 2 \mathrm{H})$.

1-(3-(3-Bromophenoxy)propyl)-4-methylpiperazine (5). To the solution of 4 (2.0 g $6.78 \mathrm{mmol})$ in $\mathrm{MeCN}(5 \mathrm{~mL})$ was added 1-methylpiperazine (1.36 g $13.5 \mathrm{mmol})$ and $\mathrm{K}_{2} \mathrm{CO}_{3}(1.87 \mathrm{~g}, 13.5 \mathrm{mmol})$, and the mixture was stirred at $80{ }^{\circ} \mathrm{C}$ for $3 \mathrm{~h}$. After completion of the reaction, the solvent was removed in vacuo and the residue was purified by silica gel column chromatography (PE/EA, 2:1) to afford a product $597 \mathrm{mg}$ in 28.4\% yield, ${ }^{1} \mathrm{H}$ NMR (400 $\left.\mathrm{MHz}, \mathrm{CDCl}_{3}\right) \delta 7.12(\mathrm{dd}, J=10.1,6.4 \mathrm{~Hz}, 1 \mathrm{H}), 7.07-7.03(\mathrm{~m}$, 2H), 6.82 (d, $J=8.2 \mathrm{~Hz}, 1 \mathrm{H}), 3.99$ (t, $J=6.3 \mathrm{~Hz}, 2 \mathrm{H}), 2.60-2.40(\mathrm{~m}, 10 \mathrm{H}), 2.28(\mathrm{~s}, 3 \mathrm{H}), 1.97-1.93(\mathrm{~m}$, 2H). MS (ESI) $\mathrm{m} / \mathrm{z}[\mathrm{M}+\mathrm{H}]^{+} 314.85$.

$N$-(2-bromoethyl)-4-methyl-2-nitroaniline (6). $5 \mathrm{~g}$ of 4-methyl-2-nitroaniline (32.8 mmol), $18 \mathrm{~mL}$ (108.6 mmol) $\mathrm{N}, \mathrm{N}$-disopropylethylamine, and $0.62 \mathrm{~g}$ of 4-dimethylaminepyridine (5.06 mmol) were added in $250 \mathrm{~mL} 3$-neck boiling flask, then an excess of $47 \mathrm{~mL}$ of 1,2-Dibromoethane (54 mmol) was added into the above mixture before being heated at $120^{\circ} \mathrm{C}$ for $24 \mathrm{~h}$. The progress was monitored by TLC (PE/EA, 3:1). After the reaction was completed, the reaction was cooled down to room temperature and filtered. The filtrate was diluted by $\mathrm{CH}_{2} \mathrm{Cl}_{2}$ and washed with water $(3 \times 100 \mathrm{ml})$. The organic layer was combined and dried over by $\mathrm{Na}_{2} \mathrm{SO}_{4}$, filtered and concentrated to afford $6.0 \mathrm{~g}$ crude product. The crude product was purified by silica gel column chromatography (PE: EA=3:1) to obtain pure product as a yellow solid $3.5 \mathrm{~g}$, Yield, $42 \%$. ${ }^{1} \mathrm{H}$ NMR $\left(400 \mathrm{MHz}, \mathrm{CDCl}_{3}\right) \delta 8.14(\mathrm{~s}, 1 \mathrm{H}), 8.01(\mathrm{~s}, 1 \mathrm{H}), 7.30(\mathrm{dd}, J=$ 
8.7, 1.9 Hz, 1H), $6.77(\mathrm{~d}, J=8.7 \mathrm{~Hz}, 1 \mathrm{H}), 3.76(\mathrm{q}, J=6.4 \mathrm{~Hz}, 2 \mathrm{H}), 3.57(\mathrm{t}, J=6.6 \mathrm{~Hz}, 2 \mathrm{H}), 2.28(\mathrm{~s}, 3 \mathrm{H})$.

4-Methyl- $N$-(2-morpholinoethyl)-2-nitroaniline (7). To the solution of 6 (2.0 g $7.75 \mathrm{mmol})$ in $\mathrm{MeCN}$ $(10 \mathrm{~mL})$ was added morpholine $(1.36 \mathrm{~g} 13.5 \mathrm{mmol})$ and $\mathrm{K}_{2} \mathrm{CO}_{3}(1.87 \mathrm{~g}, 13.5 \mathrm{mmol})$, and the mixture was stirred at $80{ }^{\circ} \mathrm{C}$ for $3 \mathrm{~h}$. After completion of the reaction, the solvent was removed in vacuo and the residue was purified by silica gel column chromatography (PE/EA, 2:1) to afford a product (924 mg), Yield, 45\% ${ }^{1} \mathrm{H}$ NMR $\left(400 \mathrm{MHz}, \mathrm{CDCl}_{3}\right) \delta 8.37(\mathrm{~s}, 1 \mathrm{H}), 8.01(\mathrm{~s}, 1 \mathrm{H}), 7.28(\mathrm{~m}, 1 \mathrm{H}), 6.77(\mathrm{~d}, J=8.7 \mathrm{~Hz}, 1 \mathrm{H}), 3.82-$ $3.74(\mathrm{~m}, 4 \mathrm{H}), 3.38(\mathrm{dd}, J=10.9,6.0 \mathrm{~Hz}, 2 \mathrm{H}), 2.73(\mathrm{t}, J=6.2 \mathrm{~Hz}, 2 \mathrm{H}), 2.60-2.50(\mathrm{~m}, 4 \mathrm{H}), 2.29(\mathrm{~s}, 3 \mathrm{H})$. MS (ESI) $\mathrm{m} / \mathrm{z}[\mathrm{M}+\mathrm{H}]^{+} 266.15$

4-Methyl- $\boldsymbol{N}^{\mathbf{1}}$-(2-morpholinoethyl)benzene-1,2-diamine (8). $560 \mathrm{mg}$, Yield, $90 \%{ }^{1} \mathrm{H}$ NMR (400 MHz, $\left.\mathrm{CDCl}_{3}\right) \delta 7.64(\mathrm{~s}, 1 \mathrm{H}), 7.36(\mathrm{~d}, J=8.3 \mathrm{~Hz}, 1 \mathrm{H}), 7.18(\mathrm{~d}, J=8.4 \mathrm{~Hz}, 1 \mathrm{H}), 4.40(\mathrm{t}, J=6.6 \mathrm{~Hz}, 2 \mathrm{H}), 3.62$ $(\mathrm{m}, 4 \mathrm{H}), 2.80(\mathrm{t}, J=6.6 \mathrm{~Hz}, 2 \mathrm{H}), 2.53(\mathrm{~s}, 3 \mathrm{H}), 2.40(\mathrm{~m}, 4 \mathrm{H}) . \mathrm{MS}(\mathrm{ESI}) \mathrm{m} / \mathrm{z}[\mathrm{M}+\mathrm{H}]^{+} 236.10$

4-Methyl-2-nitro- $\boldsymbol{N}$-phenylaniline (9a). $750 \mathrm{mg}$, Yield, 82\%. ${ }^{1} \mathrm{H}$ NMR (400 MHz, $\left.\mathrm{CDCl}_{3}\right) \delta 7.97$ (s, $1 \mathrm{H}), 7.41$ (t, $J=7.9 \mathrm{~Hz}, 2 \mathrm{H}), 7.28-7.22(\mathrm{~m}, 3 \mathrm{H}), 7.21-7.19(\mathrm{~m}, 1 \mathrm{H}), 7.18-7.16(\mathrm{~m}, 1 \mathrm{H}), 2.29$ (s, 3H). MS (ESI) $\mathrm{m} / \mathrm{z}[\mathrm{M}+\mathrm{H}]^{+} 229.12$

4-Methyl-N-(3-(3-(4-methylpiperazin-1-yl)propoxy)phenyl)-2-nitroaniline (9b). To the solution of 4-methyl-2-nitroaniline $(1.38 \mathrm{~g}, 9.07 \mathrm{mmol})$ in toluene $(18 \mathrm{~mL})$ was added 5 (2.86 g, $9.07 \mathrm{mmol}), \mathrm{Cs}_{2} \mathrm{CO}_{3}$ (5.9 g, $18.1 \mathrm{mmol})$, BINAP (847 mg, $1.36 \mathrm{mmol}), \mathrm{Pd}_{2}(\mathrm{dba})_{3}(830 \mathrm{mg}, 0.9 \mathrm{mmol})$ in sequence, and the mixture was heated to $110^{\circ} \mathrm{C}$ stirring overnight under argon atmosphere. After completion of the reaction, the mixture was filtered through Celite, and then the filtrate was removed in vacuo. The residue was purified by silica gel column chromatography (DCM/MeOH, 10:1) to afford a product (2.73 g). Yield, 77\%; ${ }^{1} \mathrm{H}$ NMR (400 MHz, $\left.\mathrm{CDCl}_{3}\right) \delta 9.32(\mathrm{~s}, 1 \mathrm{H}), 8.00(\mathrm{~s}, 1 \mathrm{H}), 7.29-7.27(\mathrm{~m}, 1 \mathrm{H}), 7.22(\mathrm{~s}, 2 \mathrm{H}), 6.83(\mathrm{~d}$, $J=7.7 \mathrm{~Hz}, 1 \mathrm{H}), 6.79(\mathrm{~s}, 1 \mathrm{H}), 6.73(\mathrm{dd}, J=8.3,2.0 \mathrm{~Hz}, 1 \mathrm{H}), 4.01(\mathrm{t}, J=6.3 \mathrm{~Hz}, 2 \mathrm{H}), 2.63-2.43(\mathrm{~m}, 10 \mathrm{H})$, $2.30(\mathrm{~d}, J=2.7 \mathrm{~Hz}, 3 \mathrm{H}), 2.29$ (s, 3H), 1.99-1.95 (m, 2H). MS (ESI) m/z [M + H $]^{+} 385.25$.

4-Methyl-N ${ }^{1}$-phenylbenzene-1,2-diamine (10a). $650 \mathrm{mg}$, Yield, 77\%; ${ }^{1} \mathrm{H}$ NMR $\left(400 \mathrm{MHz}, \mathrm{CDCl}_{3}\right) \delta$ $8.27(\mathrm{~s}, 2 \mathrm{H}), 7.87(\mathrm{~s}, 1 \mathrm{H}), 7.43(\mathrm{t}, J=7.9 \mathrm{~Hz}, 2 \mathrm{H}), 7.28-7.22(\mathrm{~m}, 3 \mathrm{H}), 7.21-7.19(\mathrm{~m}, 1 \mathrm{H}), 7.18-7.16(\mathrm{~m}$, 1H), $2.26(\mathrm{~s}, 3 \mathrm{H}) . \mathrm{MS}(\mathrm{ESI}) \mathrm{m} / \mathrm{z}[\mathrm{M}+\mathrm{H}]^{+} 199.15$

4-Methyl- $N^{1}$-(3-(3-(4-methylpiperazin-1-yl)propoxy)phenyl)benzene-1,2-diamine (10b). To the solution of $9 \mathbf{b}(2.73 \mathrm{~g}, 7.05 \mathrm{mmol})$ in $\mathrm{EtOH}(35 \mathrm{~mL})$ was add $\mathrm{Pd} / \mathrm{C}(270 \mathrm{mg}, 10 \%)$, and the mixture was stirred overnight at room temperature under hydrogen atmosphere. After completion of the reaction, the mixture was filtered through Celite, and the filtrate was removed in vacuo. The residue was purified by silica gel column chromatography (DCM/MeOH, 10:1) to afford a product (2.0 g). Yield, 74\%; ${ }^{1} \mathrm{H}$ NMR (400 MHz, DMSO-d $d_{6} \delta 7.02(\mathrm{~s}, 1 \mathrm{H}), 6.97(\mathrm{t}, J=8.0 \mathrm{~Hz}, 1 \mathrm{H}), 6.85(\mathrm{~d}, J=7.8 \mathrm{~Hz}, 1 \mathrm{H}), 6.56(\mathrm{~s}, 1 \mathrm{H}), 6.36$ $(\mathrm{d}, J=7.4 \mathrm{~Hz}, 1 \mathrm{H}), 6.24(\mathrm{~d}, J=7.9 \mathrm{~Hz}, 1 \mathrm{H}), 6.19(\mathrm{~d}, J=8.1 \mathrm{~Hz}, 1 \mathrm{H}), 6.15(\mathrm{~s}, 1 \mathrm{H}), 4.64(\mathrm{~s}, 2 \mathrm{H}), 3.87$ (t, $J=6.3 \mathrm{~Hz}, 2 \mathrm{H}), 2.45-2.25$ (m, 10H), 2.18 (s, 3H), 2.14 (s, 3H), 1.79 (dd, $J=13.5,6.7 \mathrm{~Hz}, 2 \mathrm{H})$. MS (ESI) $\mathrm{m} / \mathrm{z}[\mathrm{M}+\mathrm{H}]^{+} 355.65$. 
(E)-8-(2-(5-methyl-1-phenyl-1H-benzo[d]imidazol-2-yl)vinyl)-5-nitroquinoline (BVQ1812). To the solution of 3a (29 mg, $0.12 \mathrm{mmol})$ in dichloromethane (DCM, $3 \mathrm{~mL}$ ) was added HATU (137 mg, 0.36 mmol), DIPEA (62 mg, $0.48 \mathrm{mmol})$, and 10a ( $24 \mathrm{mg}, 0.12 \mathrm{mmol}$ ) with stirring at room temperature for $12 \mathrm{~h}$. After completion of reaction, the mixture was extracted with ethyl acetate (EA, $3 \times 30 \mathrm{~mL}$ ). The organic layer was washed with brine, dried over anhydrous sodium sulfate and concentrated in vacuo to afford crude intermediate directly used in the next step without purification. To the residue above was added acetic acid $(2 \mathrm{~mL})$ which was stirred at $90{ }^{\circ} \mathrm{C}$ overnight. Then the reaction mixture was alkalized with $\mathrm{NaOH}$ to $\mathrm{pH} 9-10$, and extracted with $\mathrm{EA}(3 \times 30 \mathrm{~mL})$. The organic layer was washed with brine, dried over anhydrous sodium sulfate, filtered and concentrated in vacuo. The residue was purified by silica gel column chromatography (DCM/MeOH, 30:1) to afford a product $(32 \mathrm{mg})$ in two steps. Yield, 65\%. ${ }^{1} \mathrm{H}$ NMR $\left(400 \mathrm{MHz}, \mathrm{CDCl}_{3}\right) \delta 9.14(\mathrm{~d}, J=16.2 \mathrm{~Hz}, 1 \mathrm{H}), 9.03(\mathrm{~d}, J=8.8 \mathrm{~Hz}, 1 \mathrm{H}), 9.00(\mathrm{~d}, J=3.5$ $\mathrm{Hz}, 1 \mathrm{H}), 8.32(\mathrm{~d}, J=8.2 \mathrm{~Hz}, 1 \mathrm{H}), 7.91(\mathrm{~d}, J=8.2 \mathrm{~Hz}, 1 \mathrm{H}), 7.71(\mathrm{~s}, 1 \mathrm{H}), 7.68-7.62(\mathrm{~m}, 3 \mathrm{H}), 7.62-7.56$ (m, 1H), $7.53-7.45(\mathrm{~m}, 3 \mathrm{H}), 7.16-7.08(\mathrm{~m}, 2 \mathrm{H}), 2.52(\mathrm{~s}, 3 \mathrm{H}) .{ }^{13} \mathrm{C} \mathrm{NMR}\left(126 \mathrm{MHz}, \mathrm{CDCl}_{3}\right) \delta 150.6$, 150.0, 145.8, 144.7, 141.5, 135.5, 134.6, 133.7, 132.5, 132.1, 130.0, 129.1, 127.6, 125.6, 125.0, 124.5, 124.0, 121.6, 120.1, 119.3, 110.0, 100.0, 21.7. HRMS (ESI-TOF) $\mathrm{m} / \mathrm{z}[\mathrm{M}+\mathrm{H}]^{+}$calcd. for $\mathrm{C}_{25} \mathrm{H}_{18} \mathrm{~N}_{4} \mathrm{O}_{2}$ 407.1503, found 407.1505

(E)-4-(2-(5-methyl-2-(2-(5-nitroquinolin-8-yl)vinyl)-1H-benzo[d]imidazol-1-yl)ethyl)morpholine (BVQ1813). To the solution of 3a (200 mg, $0.82 \mathrm{mmol})$ in dichloromethane (DCM, $8 \mathrm{~mL}$ ) was added HATU ( $935 \mathrm{mg}, 2.46 \mathrm{mmol})$, DIPEA (423 mg, $3.28 \mathrm{mmol})$, and 8 (193 $\mathrm{mg}, 0.82 \mathrm{mmol})$ with stirring at room temperature for $12 \mathrm{~h}$. After completion of reaction, the mixture was extracted with ethyl acetate $(\mathrm{EA}, 3 \times 50 \mathrm{~mL}$ ). The organic layer was washed with brine, dried over anhydrous sodium sulfate and concentrated in vacuo to afford crude intermediate directly used in the next step without purification. To the residue above was added acetic acid $(8 \mathrm{~mL})$ which was stirred at $90{ }^{\circ} \mathrm{C}$ overnight. Then the reaction mixture was alkalized with $\mathrm{NaOH}$ to $\mathrm{pH} 9-10$, and extracted with $\mathrm{EA}(3 \times 50 \mathrm{~mL})$. The organic layer was washed with brine, dried over anhydrous sodium sulfate, filtered and concentrated in vacuo. The residue was purified by silica gel column chromatography (DCM/methanol, 10:1) to afford products BVQ1813 (60 mg). Yield, $16 \% .{ }^{1} \mathrm{H}$ NMR (400 MHz, $\left.\mathrm{CDCl}_{3}\right) \delta 9.15-9.07(\mathrm{~m}, 2 \mathrm{H}), 9.00(\mathrm{~d}, J=16.1 \mathrm{~Hz}, 1 \mathrm{H}), 8.44$ $(\mathrm{d}, J=8.2 \mathrm{~Hz}, 1 \mathrm{H}), 8.08(\mathrm{~d}, J=8.2 \mathrm{~Hz}, 1 \mathrm{H}), 7.94(\mathrm{~d}, J=16.1 \mathrm{~Hz}, 1 \mathrm{H}), 7.72(\mathrm{dd}, J=8.7,4.2 \mathrm{~Hz}, 1 \mathrm{H})$, $7.64(\mathrm{~s}, 1 \mathrm{H}), 7.32-7.24(\mathrm{~m}, 1 \mathrm{H}), 7.16(\mathrm{~d}, J=7.6 \mathrm{~Hz}, 1 \mathrm{H}), 4.46(\mathrm{t}, J=6.8 \mathrm{~Hz}, 2 \mathrm{H}), 3.65(\mathrm{t}, J=6.8 \mathrm{~Hz}$, $2 \mathrm{H}), 2.82(\mathrm{t}, J=6.8 \mathrm{~Hz}, 1 \mathrm{H}), 2.50-2.62(\mathrm{~m}, 7 \mathrm{H}) .{ }^{13} \mathrm{C} \mathrm{NMR}\left(126 \mathrm{MHz}, \mathrm{CDCl}_{3}\right) \delta 150.6,150.3,145.9$, 144.7, 141.2, 133.3, 133.1, 132.2, 125.7, 125.0, 124.6, 124.1, 121.7, 120.3, 119.5, 109.0, 66.8, 57.8, 54.0, 41.8, 29.7, 21.7. HRMS (ESI-TOF) $\mathrm{m} / \mathrm{z}[\mathrm{M}+\mathrm{H}]^{+}$calcd. for $\mathrm{C}_{25} \mathrm{H}_{25} \mathrm{~N}_{5} \mathrm{O}_{3} 444.2030$, found 444.2031

\section{(E)-8-(2-(5-methyl-1-(3-(3-(4-methylpiperazin-1-yl)propoxy)phenyl)-1H-benzo[d]imidazol-2-} yl)vinyl)-5-nitroquinoline (BVQ1814). To the solution of 3a (244 mg, $1.0 \mathrm{mmol})$ in dichloromethane (DCM, $10 \mathrm{~mL}$ ) was added HATU (1.14 g, $3 \mathrm{mmol}$ ), DIPEA (516 mg, $4.0 \mathrm{mmol}$ ), and $\mathbf{1 0 b}$ (354 mg, 1.0 mmol) with stirring at room temperature for $12 \mathrm{~h}$. After completion of reaction, the mixture was extracted with ethyl acetate $(E A, 3 \times 50 \mathrm{~mL})$. The organic layer was washed with brine, dried over anhydrous sodium sulfate and concentrated in vacuo to afford crude intermediate directly used in the next step without purification. To the residue above was added acetic acid $(10 \mathrm{~mL})$ which was stirred at $90{ }^{\circ} \mathrm{C}$ overnight. Then the reaction mixture was alkalized with $\mathrm{NaOH}$ to $\mathrm{pH} 9-10$, and extracted with $\mathrm{EA}(3 \times 50$ $\mathrm{mL}$ ). The organic layer was washed with brine, dried over anhydrous sodium sulfate, filtered and 
concentrated in vacuo. The residue was purified by silica gel column chromatography (DCM/methanol, 10:1) to afford products BVQ1814 (253 mg), Yield, 45\%. ${ }^{1} \mathrm{H}$ NMR (400 MHz, $\left.\mathrm{CDCl}_{3}\right) \delta 9.12(\mathrm{~d}, J=$ $16.4 \mathrm{~Hz}, 1 \mathrm{H}), 9.06-9.02(\mathrm{~m}, 2 \mathrm{H}), 8.33(\mathrm{~d}, J=8.4 \mathrm{~Hz}, 1 \mathrm{H}), 7.91(\mathrm{~d}, J=8.4 \mathrm{~Hz}, 1 \mathrm{H}), 7.67(\mathrm{~S}, 1 \mathrm{H}), 7.66$ $-7.64(\mathrm{~m}, 1 \mathrm{H}), 7.51(\mathrm{t}, J=8.0 \mathrm{~Hz}, 1 \mathrm{H}), 7.44(\mathrm{~d}, J=16.0 \mathrm{~Hz}, 1 \mathrm{H}), 7.16-7.08(\mathrm{~m}, 3 \mathrm{H}), 7.05(\mathrm{dd}, J=$ 8.0, 2.0 Hz, 1H), $7.02-7.01(\mathrm{~m}, 1 \mathrm{H}), 4.07(\mathrm{t}, J=6.0 \mathrm{~Hz}, 2 \mathrm{H}), 2.56-2.45(\mathrm{~m}, 13 \mathrm{H}), 2.31(\mathrm{~s}, 3 \mathrm{H}), 2.03-$ $1.97(\mathrm{~m}, 2 \mathrm{H}) ;{ }^{13} \mathrm{C} \mathrm{NMR}\left(126 \mathrm{MHz}, \mathrm{CDCl}_{3}\right) \delta 160.2,150.6,150.1,145.8,144.6,143.6,141.8,136.7$, $134.8,133.3,132.1,131.5,130.6,125.3,124.6,124.5,124.1,121.6,120.5,119.7,119.6,115.3,113.6$, 101.0, 66.7, 55.0, 54.9, 53.0, 45.9, 26.6, 21.7. HRMS (ESI-TOF) $\mathrm{m} / \mathrm{z}[\mathrm{M}+\mathrm{H}]^{+}$calcd. for $\mathrm{C}_{33} \mathrm{H}_{34} \mathrm{~N}_{6} \mathrm{O}_{3}$ 563.2765 , found 563.2762 .

(E)-5-(2-(5-methyl-1-(3-(3-(4-methylpiperazin-1-yl)propoxy)phenyl)-1H-benzo[d]imidazol-2yl)vinyl)-8-nitroisoquinoline (BVQ1815). $28 \mathrm{mg}$, Yield, 35\%. ${ }^{1} \mathrm{H} \mathrm{NMR}\left(500 \mathrm{MHz}, \mathrm{CDCl}_{3}\right) \delta 10.05$ (s, $1 \mathrm{H}), 8.77(\mathrm{~d}, J=5.8 \mathrm{~Hz}, 1 \mathrm{H}), 8.58(\mathrm{~d}, J=15.7 \mathrm{~Hz}, 1 \mathrm{H}), 8.28(\mathrm{~d}, J=8.0 \mathrm{~Hz}, 1 \mathrm{H}), 8.18(\mathrm{~d}, J=5.9 \mathrm{~Hz}$, 1H), $7.88(\mathrm{~d}, J=8.1 \mathrm{~Hz}, 1 \mathrm{H}), 7.66(\mathrm{~s}, 1 \mathrm{H}), 7.52(\mathrm{t}, J=8.0 \mathrm{~Hz}, 1 \mathrm{H}), 7.19-7.05(\mathrm{~m}, 4 \mathrm{H}), 7.05-6.93(\mathrm{~m}$, $2 \mathrm{H}), 4.07(\mathrm{t}, J=6.1 \mathrm{~Hz}, 2 \mathrm{H}), 2.92-2.32(\mathrm{~m}, 13 \mathrm{H}), 2.29(\mathrm{~s}, 3 \mathrm{H}), 2.06-1.94(\mathrm{~m}, 2 \mathrm{H}) .{ }^{13} \mathrm{C} \mathrm{NMR}(126$ $\left.\mathrm{MHz}, \mathrm{CDCl}_{3}\right) \delta 160.3,149.1,148.8,145.7,144.7,143.3,139.6,136.4,134.8,134.7,133.7,130.9$, 129.6, 125.8, 125.8, 124.7, 121.5, 120.4, 119.6, 119.4, 116.5, 115.4, 113.7, 110.2, 66.7, 54.8, 54.7, 52.7, 45.6, 26.5, 21.7. HRMS (ESI-TOF) $\mathrm{m} / \mathrm{z}[\mathrm{M}+\mathrm{H}]^{+}$calcd. for $\mathrm{C}_{33} \mathrm{H}_{34} \mathrm{~N}_{6} \mathrm{O}_{3} 563.2765$, found 563.2783 


\section{Experiment section}

\subsection{Molecular docking and dynamics simulations}

The X-ray crystal structure of PDE10A-14 complex (PDB code: 7BPI) ${ }^{3}$ was selected for molecular modeling, and Surflex-dock embedded in the software Tripos Sybyl 2.0 was used. ${ }^{4}$ Two metal ions crucial for the PDE's catalytic activity in the catalytic domain and water molecules coordinating these two metal ions were retained. Hydrogen atoms were added, and the ionizable residues were protonated at the neutral $\mathrm{pH}$. The protomol was generated using the parameters by default. The parameters of proto_thresh and proto_bloat was assigned 0.5 and 0 , respectively. After the protomol was prepared, molecular docking was performed for test molecules.

After $8 \mathrm{~ns}$ molecular dynamics simulations with similar parameters to our previous work, ${ }^{3,5} \mathrm{MM}$ GBSA binding free energy calculations were performed by extracting 100 snapshots of the last $1 \mathrm{~ns}$ trajectories with default parameters assigned. According to the MM-GBSA method, the binding free energies $\left(\Delta G_{\text {bind }}\right)$ are calculated using equation 1 , in which $G_{\text {complex }}, G_{\text {rec }}$ and $G_{\text {lig }}$ are the representations of the free energies of complex, receptor and ligand, respectively. Each free energy is calculated as the sum of the MM energy $E_{\mathrm{MM}}$, the solvation free energy $G_{\text {solv }}$, and the entropy contribution $T S$, respectively, leading to equation 2. $\Delta E_{\mathrm{MM}}$ represents the gas phase interaction energy. It is decomposed into $E_{\mathrm{MM}}$, complex, $E_{\mathrm{MM}}$, rec and $E_{\mathrm{MM}}$, lig. The solvation free energy represents the sum of the electrostatic solvation free energy and nonpolar solvation free energy. The entropy contribution for each system was omitted since this computational process is extremely time-consuming for large protein-ligand systems.

$$
\begin{aligned}
& \Delta G_{\text {bind }}=G_{\text {complex }}-G_{\text {rec }}-G_{\text {lig }} \\
& \Delta G_{\text {bind }}=\Delta E_{\mathrm{MM}}+\Delta G_{\text {solv }}-T \Delta S
\end{aligned}
$$

\subsection{Protein Expression and Purification}

Briefly, the plasmid (pET15b-PDE10A) was transferred to E. coli strain BL21 (Codonplus, Stratagene). Then, the $E$. coli cells carrying the recombinant plasmid were grown in $2 \mathrm{xYT}$ medium (containing $100 \mu \mathrm{g} \cdot \mathrm{mL}^{-1}$ ampicillin and $30 \mu \mathrm{g} \cdot \mathrm{mL}^{-1}$ chloramphenicol) at $37^{\circ} \mathrm{C}$ until an absorption of $\mathrm{OD}_{600 \mathrm{~nm}}=0.6-0.8$. Then, $1 \mathrm{mM}$ isopropyl- $\beta-D$-thiogalactopyranoside was added to induce the expression of the PDE10A protein and the culture was incubated at $15^{\circ} \mathrm{C}$ for $48 \mathrm{~h}$. The catalytic domain of PDE10A2 (449-770) was purified with three chromatographic columns of nickel-nitrilotriacetic acid (Qiagen), Q-Sepharose (Amersham Biosciences), and Sephacryl S300 (GE Healthcare). A typical batch of purification yielded about $10 \mathrm{mg}$ of PDE10A2 from 10 liters of cell culture and the purity was verified by SDS-PAGE. The catalytic domains of PDE1B (10-487), PDE2A (580-919), PDE3A (679-1087), PDE4D2 (86-413), PDE5A1(535-860), PDE7A1 (130-482), PDE8A1 (480-820), and PDE9A2 (181-506) were purified by using similar protocols. ${ }^{3,5,6}$

\subsection{Fluorescent excitation and emission spectra of BVQ1812-1815}

To prepare test samples, DMSO stock of probe compounds $(20 \mathrm{mM})$ was diluted to $10 \mu \mathrm{M}$ with $\mathrm{H}_{2} \mathrm{O}$. 
then, the spectra were scanned with UV/VIS spectrophotometer and fluorescence spectrophotometer.

Tris- $\mathrm{HCl}$ buffer $(50 \mathrm{mM})$ with different $\mathrm{pH}$ were prepared by neutralizing Tris-base $(50 \mathrm{mM})$ with $\mathrm{HCl}$ aq. (1 M). To prepare test samples, DMSO stock of probe BVQ1814 $(20 \mathrm{mM})$ was diluted to $10 \mu \mathrm{M}$ with different kind of solvent (about $3 \mathrm{~mL}$ ). then, the spectra were scanned with fluorescence spectrophotometer

PDE10A recombinant protein was prepared in our group according to a sophisticated method. PDE10A protein samples were diluted to different concentration and incubated with probe BVQ1814 $(20 \mu \mathrm{M})$ in PBS buffer (1X, pH 7.4). After blending the two samples in a quartz cell, the fluorescent spectra were scanned with fluorescence spectrophotometer.

\subsection{The fluorescence quantum yields and pKa measurements}

All reagents and solvents available from commercial sources were used as received unless otherwise noted. To prepare test samples, DMSO stock of probe BVQ1814 $(20 \mathrm{mM})$ was diluted to $10 \mu \mathrm{M}$ with PBS buffer (1X, pH 7.4) (about $3 \mathrm{~mL}$ ). then, the spectra were scanned with fluorescence spectrophotometer and UV/VIS spectrophotometer. $0.1 \mathrm{M} \mathrm{NaOH}$ stock of fluorescein sodium $\left(\Phi_{470}=\right.$ $0.91)(50 \mathrm{mM}$ ) was diluted to $10 \mu \mathrm{M}$ with $0.1 \mathrm{M} \mathrm{NaOH}$ (about $3 \mathrm{~mL}$ ). then, the spectra were scanned with fluorescence spectrophotometer and UV/VIS spectrophotometer.

The fluorescence quantum yield (QY) can be calculated from equation 3:

$$
\Phi_{\mathrm{i}}=\frac{F_{i} f_{\mathrm{s}} n_{\mathrm{i}}^{2}}{F_{\mathrm{s}} f_{\mathrm{i}} n_{\mathrm{s}}^{2}} \Phi_{\mathrm{s}}
$$

where $\Phi_{\mathrm{i}}$ and $\Phi_{\mathrm{s}}$ are the fluorescence QY of the sample and the standard, respectively; $F_{\mathrm{i}}$ and $F_{\mathrm{s}}$ are the integrated intensities (areas) of sample and standard spectra, respectively (in units of photons); $f_{s}$ is the absorption factor (also known under the obsolete term "absorptance"), the fraction of the light impinging on the sample that is absorbed $\left(f_{x}=1-10^{-4 x}\right.$, where $\mathrm{A}=$ absorbance); the refractive indices of the sample and reference solution are $n_{\mathrm{i}}$ and $n_{\mathrm{s}}$, respectively.

The pKa values of the probes were measured in standard UV-pKa assays by the SiriusT3 system (Sirius Analytical, UK). The probes were dissolved in DMSO to prepare the stock solution (10 mM). Then, $5 \mu \mathrm{L}$ of the stock solution and $25 \mu \mathrm{L}$ of the UV metrically phosphate buffer solution was added into the sample tube successively. When the $\mathrm{pH}$ was adjusted, the instrument started the titration with acid or base from $\mathrm{pH} 2$ to $\mathrm{pH} 12$. For each compound, the titration assays were repeated three times. According to the collected data of UV spectrum, pKa values were calculated automatically by the software loaded in the SiriusT3 system.

\subsection{PDE10A protein labeling with $\mathrm{Cy} 3$}

Cy3 NHS ester was dissolved in DMSO to prepare the labeling reagent $\left(1 \mathrm{mg} \cdot \mathrm{mL}^{-1}\right)$. Tris- $\mathrm{HCl}(0.1$ $\mathrm{mol} \cdot \mathrm{L}^{-1}, \mathrm{pH}$ 7.0) buffer of PDE $10 \mathrm{~A}$ recombinant protein was replaced with $\mathrm{NaHCO}_{3}$ buffer $(0.1 \mathrm{M}, \mathrm{pH}$ $8.5)$ in a protein concentrator tube. Into the protein solution, $40 \mu \mathrm{L}$ of Cy3 NHS ester stock was added gradually (10 $\mu \mathrm{L}$ each time), and mixed carefully. Then, the tube was sealed with aluminum foil and oscillated at $4{ }^{\circ} \mathrm{C}$ overnight. Into a protein concentrator tube, the red reaction mixture as well as cooled 
PBS (1X, pH 7.4) was added and then centrifuged at $4{ }^{\circ} \mathrm{C}$ until the volume of sample was $1 \mathrm{~mL}$. The above operation was repeated three times.

The OD value of Cy3-labeled PDE10A was scanned by UV/VIS spectrophotometer. The F/P value was calculated and shown as following:

$$
\begin{gathered}
\text { Cy3 Ext. Coefficient }\left(E C_{\mathrm{Cy} 3}\right)=150000 \mathrm{M}^{-1} \cdot \mathrm{cm}^{-1}, \\
\text { PDE10A Ext. Coefficient }\left(E C_{\mathrm{PDE} 10 \mathrm{~A}}\right)=43150 \mathrm{M}^{-1} \cdot \mathrm{cm}^{-1}, \\
A_{280 \mathrm{~nm}}=0.64137 \mathrm{M}^{-1} \cdot \mathrm{cm}^{-1}, \\
A_{555 \mathrm{~nm}}=0.23629 \mathrm{M}^{-1} \cdot \mathrm{cm}^{-1}, \\
{[\mathrm{Cy} 3]=\frac{A_{555 \mathrm{~nm}}}{E C_{\mathrm{Cy} 3}}=\frac{0.23629}{150000}=1.58 \times 10^{-6},} \\
{[\mathrm{PDE} 10 \mathrm{~A}]=\frac{A_{280 \mathrm{~mm}}-0.08 \times A_{555 \mathrm{~nm}}}{E C_{\mathrm{PDE} 10 \mathrm{~A}}}=\frac{0.64137-0.08 \times 0.23629}{43150}=1.44 \times 10^{-5}} \\
\frac{\mathrm{F}}{\mathrm{P}}=\frac{[\mathrm{Cy} 3]}{[\mathrm{PDE} 10 \mathrm{~A}]}=\frac{1.58 \times 10^{-6}}{1.44 \times 10^{-5}}=0.11
\end{gathered}
$$

\subsection{Fluorescence properties of BVQ1814 with PDE10A recombinant protein}

When mixed with PDE10A recombinant protein, the Fluorescence spectra fluctuation of BVQ1814 was evaluated. The test samples were prepared by diluting the BVQ1814 DMSO stock (20 mM) to the concentration of $20 \mu \mathrm{M}$ with PBS buffer (1X, pH 7.4). After the test samples were mixed with PDE10A recombinant protein solution with different concentrations $\left(0,1.6,3.2,6.4,12.5,25,100 \mu \mathrm{g} \cdot \mathrm{mL}^{-1}\right) \mathrm{in}$ Tris-HCl (0.1 M, pH 7.0), the fluorescence emission spectra of each sample were scanned by fluorescence spectrophotometer (Fluoromax-4, HORIBA) under excitation light at $467 \mathrm{~nm}$ respectively.

FRET effect between BVQ1814 and Cy3-labeled PDE10A recombinant protein (Cy3-PDE10A) was also evaluated by the procedure similar with the above experiments. Test samples were prepared in PBS (1X, pH 7.4) in the concentration of: a) BVQ1814 (10 $\mu \mathrm{M})$; b) BVQ1814 (10 $\mu \mathrm{M})$ and TAK-063 (10 $\mu \mathrm{M})$; c) Cy3-PDE10A (25 $\left.\mu \mathrm{g} \cdot \mathrm{mL}^{-1}\right)$; d) blank (only PBS).

Then, upon excited at $467 \mathrm{~nm}$, fluorescence emission spectra were scanned after the samples were mixed with equal volume $(80 \mu \mathrm{L})$ respectively according to the following combination:

1) a solution of $\mathrm{a}+\mathrm{d}$, means BVQ1814 $(5 \mu \mathrm{M})$;

2) a solution of $\mathrm{b}+\mathrm{d}$, means BVQ1814 $(5 \mu \mathrm{M})$ and TAK-063 $(5 \mu \mathrm{M})$;

3) a solution of $\mathrm{c}+\mathrm{d}$, means Cy3-PDE10A $\left(12.5 \mu \mathrm{g} \cdot \mathrm{mL}^{-1}\right)$;

4) a solution of $\mathrm{a}+\mathrm{c}$, means BVQ1814 $(5 \mu \mathrm{M})$ mixed with Cy3-PDE10A $\left(12.5 \mu \mathrm{g} \cdot \mathrm{mL}^{-1}\right)$;

5) a solution of $b+c$, means BVQ1814 $(5 \mu \mathrm{M})$ and TAK-063 $(5 \mu \mathrm{M})$ mixed with Cy3-PDE10A $\left(12.5 \mu \mathrm{g} \cdot \mathrm{mL}^{-1}\right)$.

Fluorescence intensity data depicted in Figure 1D was calculated by deducting background as following:

$$
\begin{aligned}
& I_{\mathrm{Cy} 3-\mathrm{PDE} 10}=I_{\mathrm{c}+\mathrm{d}} ; \\
& I_{\text {Су3-PDE10 }}+\mathrm{BVQ1814}=I_{\mathrm{a}+\mathrm{c}}-I_{\mathrm{a}+\mathrm{d}} ; \\
& I_{\mathrm{Cy} 3-\mathrm{PDE} 10}+\mathrm{TAK}-063+\mathrm{BVQ} 1814=I_{\mathrm{b}+\mathrm{c}}-I_{\mathrm{b}+\mathrm{d}} \text { 。 }
\end{aligned}
$$

\subsection{Cell culture}


HeLa cells, A549 cells and the PASMCs were cultured in DMEM medium (FBS 10\%, V/V). HLF-1 cells were cultured in F12K medium (FBS 10\%, V/V). All the cells were cultivated in an incubator with an atmosphere of $5 \% \mathrm{CO}_{2}, 95 \%$ air at $37{ }^{\circ} \mathrm{C}$.

All the medium used for cell culture contained penicillin-streptomycin 1\% (V/V) unless otherwise noted.

\subsection{Cytotoxicity evaluation}

Cell viability assay was performed to evaluate the cytotoxicity of BVQ1814 using CCK-8 method. HeLa cells were harvested in logarithmic phase then plated on the 96-well plates (each well contained approximate 8000 cells in $100 \mu \mathrm{L}$ medium) and allowed to adhere for $8-12 \mathrm{~h}$. After a $24 \mathrm{~h}$-incubation or a 48h-incubation with different concentrations of compound $(0,0.39,0.78,1.56,3.14,6.25,12.5,25,50$, $100 \mu \mathrm{M})$ in DMEM medium, the viability of HeLa cells was measured by CCK-8 method.

\subsection{Cell fluorescent imaging}

The cells were harvested in logarithmic phase then plated on glass-bottom cell culture dishes (each dish contained approximate 10 000-15 000 cells in $1 \mathrm{~mL}$ medium) and allowed to adhere for 8-12 h. After the medium was removed, the cells were carefully washed with $37^{\circ} \mathrm{C} \mathrm{PBS}(1 \mathrm{X}, \mathrm{pH} 7.4)$, and then incubated at $37^{\circ} \mathrm{C}$ in the presence of the probe BVQ1814 $(10 \mu \mathrm{M}$, prepared in DMEM medium without FBS), Lysosome Tracker Red (or Mitochondria Tracker Deep Red) and Hoechst 33342 for 30 min. After incubation, the cells were carefully washed with $37{ }^{\circ} \mathrm{C}$ PBS (1X, pH 7.4), and then imaged by a confocal fluorescence microscope (FV3000, Olympus).

Using the similar procedure, Lysosome Tracker Red, Hoechst 33342 as well as probe BVQ1814 (10 $\mu \mathrm{M})$ was co-incubated with TAK-063 $(10 \mu \mathrm{M})$ or chloroquine $(10 \mu \mathrm{M})$ for $30 \mathrm{~min}$. After washed with $37^{\circ} \mathrm{C}$ PBS (1X, pH 7.4) carefully, the fluorescence imaging was performed using a confocal fluorescence microscope (FV3000, Olympus).

Fixed HeLa cells were also stained by BVQ1814 $(10 \mu \mathrm{M})$ overnight at $4{ }^{\circ} \mathrm{C}$ and DAPI for $10 \mathrm{~min}$ at RT successively. After DAPI was washed out, the fluorescent images were captured by confocal fluorescence microscope (FV3000, Olympus). Unlike the staining results in live cells, BVQ1814 could hardly enter the regions of fixed cell nucleus.

The fluorescent dyes used in the experiments were listed in Table S4. The Fluorescent images were analyzed by the imageJ software. The data were statistical analyzed using GraphPad Prism 8.0.

\subsection{Cell immunofluorescence imaging}

HeLa cells in logarithmic phase were plated on glass-bottom cell culture dishes (10 000-15 000 cells /per dish). After allowed to adhere for 8-12 h, the cells were fixed at ambient temperature for 30min with PLP (Periodate-Lysine-Paraformaldehyde fixative) and washed with PBS (1X, pH 7.4, $2 \mathrm{~mL}$ ) three times $(5 \min \times 3)$ carefully. Then, the fixed cells were treated with TritonX-100 $(0.5 \%, \mathrm{~V} / \mathrm{V})$ in $\mathrm{PBS}(1 \mathrm{X}, \mathrm{pH}$ 7.4, $1 \mathrm{~mL}$ ) for another $30 \mathrm{~min}$ at ambient temperature and washed with PBS (1X, pH 7.4, $2 \mathrm{~mL})$ three times ( $5 \mathrm{~min} \times 3)$. Afterwards, PDE10A primary antibody (1:200 diluted, Santa Cruz, sc-515023) in goat serum solution (10\% in PBS, $300 \mu \mathrm{L}$ per dish) and BVQ1814 (10 $\mu \mathrm{M}$, if necessary) was added into culture dishes and incubated at $4{ }^{\circ} \mathrm{C}$ overnight. The cells were washed with PBS (1X, pH 7.4) three times and incubated with relative fluorescent anti-antibody (1:500 diluted, Abcam, ab150115) in goat serum solution (10\% V/V in PBS, $300 \mu \mathrm{L}$ per dish) at ambient temperature for 1-2 h successively. Finally, the 
cells were washed with PBS (1X, $\mathrm{pH}$ 7.4) three times and stained with DAPI at ambient temperature for 10-15 min to complete the pretreatment procedure of samples. After DAPI was washed out, the fluorescent images were captured by confocal fluorescence microscope (FV3000, Olympus).

The Fluorescent images were also analyzed by the imageJ software. The data were statistical analyzed using GraphPad Prism 8.0.

\subsection{Quantative real-time PCR assays}

The relative levels of PDE10A mRNA were determined by qRT-PCR method. The intron-spanning primer pairs for PDE10A were designed with the assistance of Primerbank database as well as Pubmedblast program and customized by Shanghai Sangon Biotech Co., Ltd. (Table S5). Total RNAs were extracted from relative cells by using RNAiso Plus (9109, Takara) and reverse transcription into cDNA by using PrimeScript ${ }^{\mathrm{TM}}$ RT Master Mix (RR036, Takara), according to the manufacturer's instructions. qRT-PCR assays were performed on an QPCR system machine (lightCycler480II, Roche) with SYBR Premix (RR820, Takara). Results were analyzed using the comparative (2- $\Delta \Delta C T)$ method. Samples were normalized to the reference gene PBGD to account for cDNA loading differences. Each reaction was run in triplicate and repeated in at least three independent experiments.

\subsection{Western Blot assays}

The expression levels of PDE10A protein indifferent cell lines were determined by Western blotting method. After cells were lysised, the cell lysates were centrifuged at $4{ }^{\circ} \mathrm{C}$ for 15 min at $12000 \mathrm{rpm}$. The supernatants were collected for subsequent analysis. Protein concentration were measured by BCA

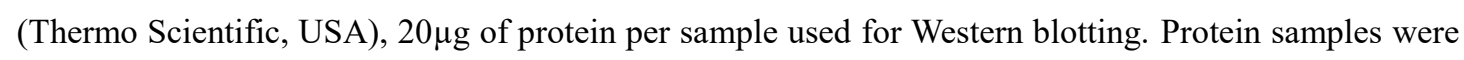
separated on SDS-PAGE gel (10\% acrylamide) and then proteins were electrophoretically transferred to polyvinylidene fluoride membranes (Millipore, USA). Membranes were blocked with 5\% nonfat milk powder in Tris-buffered saline Tween 20 (TBS-T) for $1.5 \mathrm{~h}$ at room temperature, and successively the membranes were incubated overnight at $4{ }^{\circ} \mathrm{C}$ with primary antibody as follows: PDE10A antibody (1:1 000 diluted, Santa Cruz, sc-515023), anti-GAPDH antibody ( $1 \mu \mathrm{g} \cdot \mathrm{mL}^{-1}$, Abcam, ab9484). Followed by staining with corresponding Goat Anti-Mouse $\lg$ G secondary antibodies (Boster, China) for $1 \mathrm{~h}$ at RT. The signals were visualized using ECL reagents (Thermo Scientific, USA). Densitometric quantification of the immunoblot bands was performed using Bio-Rad Quality One software. The data were statistical analyzed using GraphPad Prism 8.0.

\subsection{Cells transiently transfected with PDE10A siRNA}

PDE10A siRNA as well as the transfection reagent used in this project was purchased from Guangzhou RiboBio Co., Ltd. (Product ID: stB0009714B-1-5). HeLa cells in logarithmic phase were plated on a 6well plate (each well contained 150000 cells) and allowed to adhere for 8-12 h. Then, PDE10A siRNA $(50 \mathrm{nM})$ as well as transfection reagent in $1 \mathrm{~mL}$ of DMEM medium (FBS 10\%, V/V) without penicillinstreptomycin was added into the 6-well plate after the former medium was removed and carefully washed with $37{ }^{\circ} \mathrm{C}$ PBS (1X, pH 7.4). The cells were cultivated in an incubator with an atmosphere of $5 \% \mathrm{CO}_{2}$, $95 \%$ air at $37^{\circ} \mathrm{C}$ for $72 \mathrm{~h}$.

After incubation, the relative levels of PDE10A mRNA were determined by qPCR method. Meanwhile, the cells were co-stained with BVQ1814 $(10 \mu \mathrm{M})$, Lysosome Tracker Red and Hoechst 33342 for 30 min and the fluorescent images were captured as the aforementioned method. 


\subsection{Construction of stable transfected PDE10A overexpressing HepG2 cells}

Lentiviral vectors were used to establish stable PDE10A-overexpressing HepG2 cell lines. All constructs as well as pcDNA-PDE10A (NCBI accession no. NM_001130690) was prepared with standard DNA recombination on techniques supported by Genechem (Genechem, Shanghai, China). Briefly, PDE10A insert was isolated by PCR amplification from pcDNA-PDE10A with two pairs of restriction primers.

The primer sequences were as follows:

(forward)

\section{5' -GATCTATTTCCGGTGAATTCCGCCACCATGGAAGATGGACCTTCTAATAATG-3 '}

and (reverse)

5' -TCCTTGTAGTCCATGGATCCATCTTCAGATGCAGCTGCCTTCTG -3' .

PCR products were sequenced and confirmed to contain the entire PDE10A coding sequence. The insert was cloned into the pGC-FU-CMV-3FLAG-EF1-mCherry-T2A-puromycin plasmid, and then were co-transfected with packaging helper plasmids (Genechem, Shanghai, China) into 293T cells. The PDE10A-mCherry viral supernatant (Lenti-PDE10A-mCherry) was harvested, filtered, and concentrated. The packaging vectors, without the PDE10A insert, was prepared similarly as a negative control. HepG2 cells $(1 \times 105)$ were plated in 6 -well plates and infected with lentivirus in the presence of polybrene $(5.0$ $\left.\mu \mathrm{g} \cdot \mathrm{mL}^{-1}\right)$. After $48 \mathrm{~h}$, the HepG2 cells were cultured in medium containing puromycin $\left(1.0 \mu \mathrm{g} \cdot \mathrm{mL}^{-1}\right)$ for 2-3 weeks to generate stable cell lines. Stable PDE10A-overexpressing cell lines were confirmed by RTqPCR (Figure S10).

\subsection{Preparation of primary pulmonary artery smooth muscle cells}

Six male Wistar rats (10 weeks old) were divided into equal two groups: normal group and model group. The experiments were started after the rats were allowed to acclimate for 3 days. The rats of model group were given monocrotaline $(2 \%, \mathrm{~m} / \mathrm{m})$ by intraperitoneal injection with the dose $\left(60 \mathrm{mg} \cdot \mathrm{kg}^{-1}\right)$ to establish animal model of pulmonary artery hypertension (MCT-PAH). Meanwhile, the normal group was given by intraperitoneal injected saline at the same dosage. After 4 weeks, the rats from both groups were executed and soaked in ethanol $(75 \%, \mathrm{~V} / \mathrm{V})$ for 6-10 min. In a super clean bench, cardiopulmonary tissues were removed and rinsed in penicillin-streptomycin $\left(100 \mathrm{U} \cdot \mathrm{mL}^{-1}\right.$ in PBS) three times. Then, the pulmonary artery and the following branch was isolated and the vascular fiber layer and outer membrane were stripped quickly. In a new culture dish, pulmonary artery was opened longitudinally to remove the endothelial cell layer. The reserved medial arterial was cut into pieces (about $2 \mathrm{~mm}^{3}$ ) and plated on another clean cell culture dish containing DMEM medium (FBS 10\%, V/V). Then the dish was transferred into an incubator with an atmosphere of $5 \% \mathrm{CO}_{2}, 95 \%$ air at $37{ }^{\circ} \mathrm{C}$ and cultivated. DMEM medium was replaced every 3 days. The spindle type cells grew from small pieces of vascular tissues could be seen on the dish about 4-6 days later.

Identification of rat primary pulmonary artery smooth muscle cells was conducted by immunofluorescence analysis towards alpha-smooth muscle actin ( $\alpha$-SMA). The cells were plated on a 48- well plate after 3 generations. When cells adherent, stained with $\alpha$-SMA primary antibody at $4{ }^{\circ} \mathrm{C}$ overnight and secondary antibody at RT for $1 \mathrm{~h}$ successively, and then imaged by an auto cell imaging system (EVOS FL Auto, Life Technologies). 
The relative levels of PDE10A mRNA in PASMCs were determined by qPCR method with the similar procedure mentioned above.

\subsection{Tissue sections immunofluorescent imaging}

Tissue section samples were dewaxed and pretreated with the heated citric acid solution for antigen retrieval. Then the samples were blocked with $1 \%(\mathrm{~V} / \mathrm{V})$ BSA in PBS buffer (1X,pH 7.4) and incubated with probe BVQ1814 (10 $\mu \mathrm{M}$, prepared in PBS buffer) at RT for $8 \mathrm{~h}$, PDE10A primary antibody at $4{ }^{\circ} \mathrm{C}$ overnight and secondary antibody at RT for $1 \mathrm{~h}$ successively. Then, the fluorescent images of lung and striatum tissue sections were obtained. Images were analyzed by imageJ software.

\subsection{Pharmacodynamics study on animal models}

All animal care and experimental protocols were in accordance with "Guide for the Care and Use of Laboratory Animals" (National Institutes of Health Publication, revised 1996, No.86-23, Bethesda, MD) and were approved by the Institutional Ethical Committee for Animal Research of Sun Yat-sen University. Forty Wister rats (6 weeks, 160-180 g), purchased from Beijing Vital River Laboratory Animal Technology Co., Ltd., were used to evaluate the pharmacodynamics effects of BVQ1814 on PAH. The rats were randomly divided into four groups (8-10 rats in each group): control group, model, compound BVQ1814 (2.5 mg. $\left.\mathrm{kg}^{-1}\right)$, and positive (tadalafil, $5.0 \mathrm{mg} \cdot \mathrm{kg}^{-1}$ ). Rats were maintained on a $12 \mathrm{~h}$ light/dark cycle (light from 7:00 to 19:00) at $24 \pm 1^{\circ} \mathrm{C}$ and $60-70 \%$ relative humidity. Sterile food and water were given according to the institutional guidelines. Prior to each experiment, the rats were fasted overnight and allowed free access to water. All the rats were administrated i.v. with MCT $60 \mathrm{mg} \cdot \mathrm{kg}^{-1}$ except group control. Then, the rats were orally treated with a drug vehicle (control group or model group), compound BVQ1814 (2.5 mg. $\mathrm{kg}^{-1}$, i.p.) and tadalafil $\left(5.0 \mathrm{mg} \cdot \mathrm{kg}^{-1}\right.$, p.o.) for 3 weeks, respectively. Compound BVQ1814 dispersed in saline and tadalafil dissolved in 0.5\% CMC-Na solution was administrated. The method of right cardiac catheter was applied to measure the pulmonary artery pressure and the mean pulmonary artery pressure ( $m$ PAP) was used to conduct statistics. ${ }^{5}$ Subsequently, the rats were killed and the hearts were dissected into right ventricle (RV), left S7 ventricle and interventricular septum $(\mathrm{LV}+\mathrm{S})$; the 2 parts of the hearts were weighed with electronic scales, the ratio of RV to $(\mathrm{LV}+\mathrm{S})$ was used to conduct statistics of right ventricle hypertrophy index (RVHI\%). Then a part of lung tissues was taken and fixed with $4 \%$ paraformaldehyde. Routine HE staining was performed to observe the pathological changes and calculate the percentage of the medial wall thickness of pulmonary arterioles (WT\%). ${ }^{1,3}$ 


\section{Characterization data}

${ }^{1} \mathrm{H}$ NMR of BVQ1812

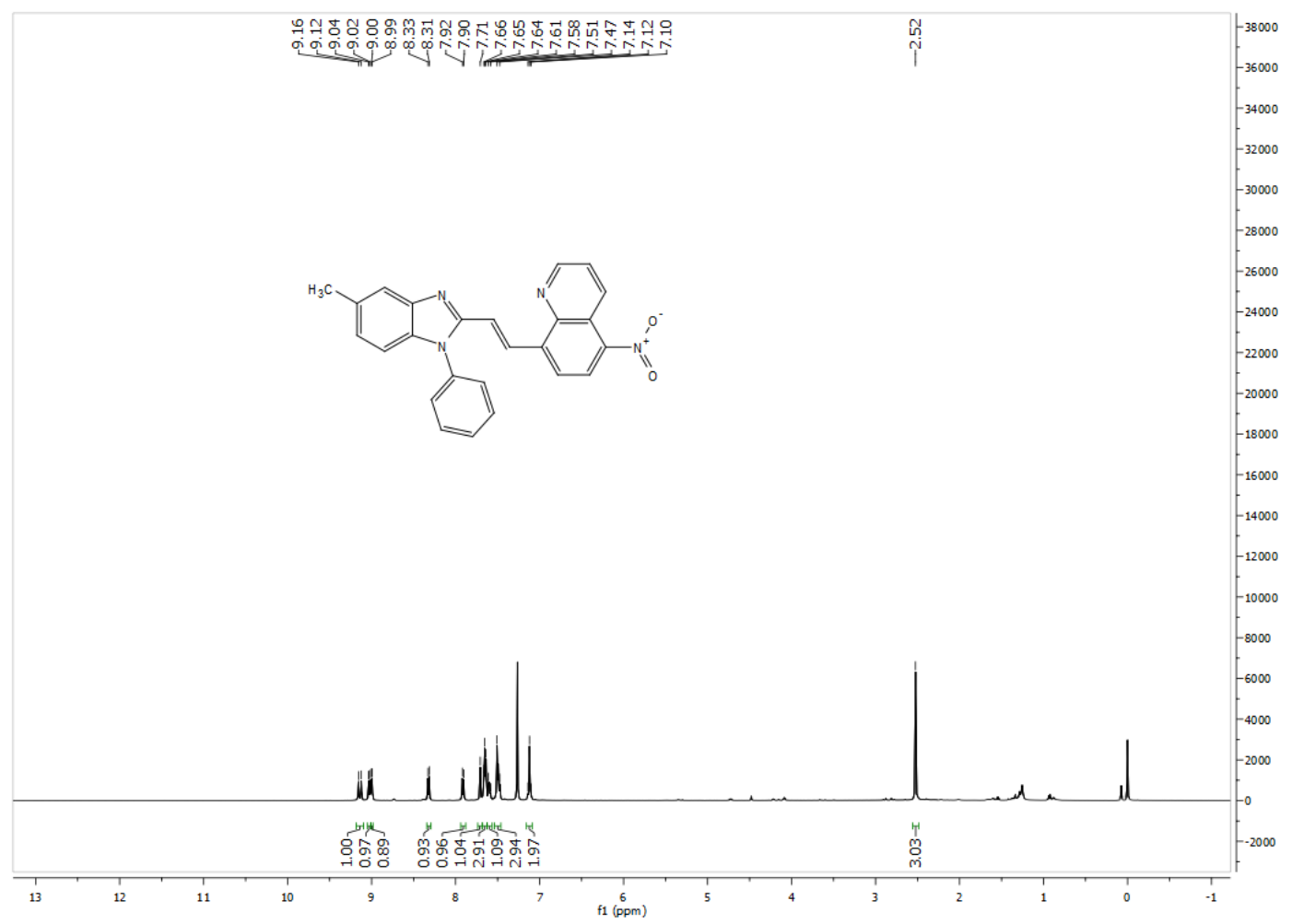

${ }^{13} \mathrm{C}$ NMR of BVQ1812

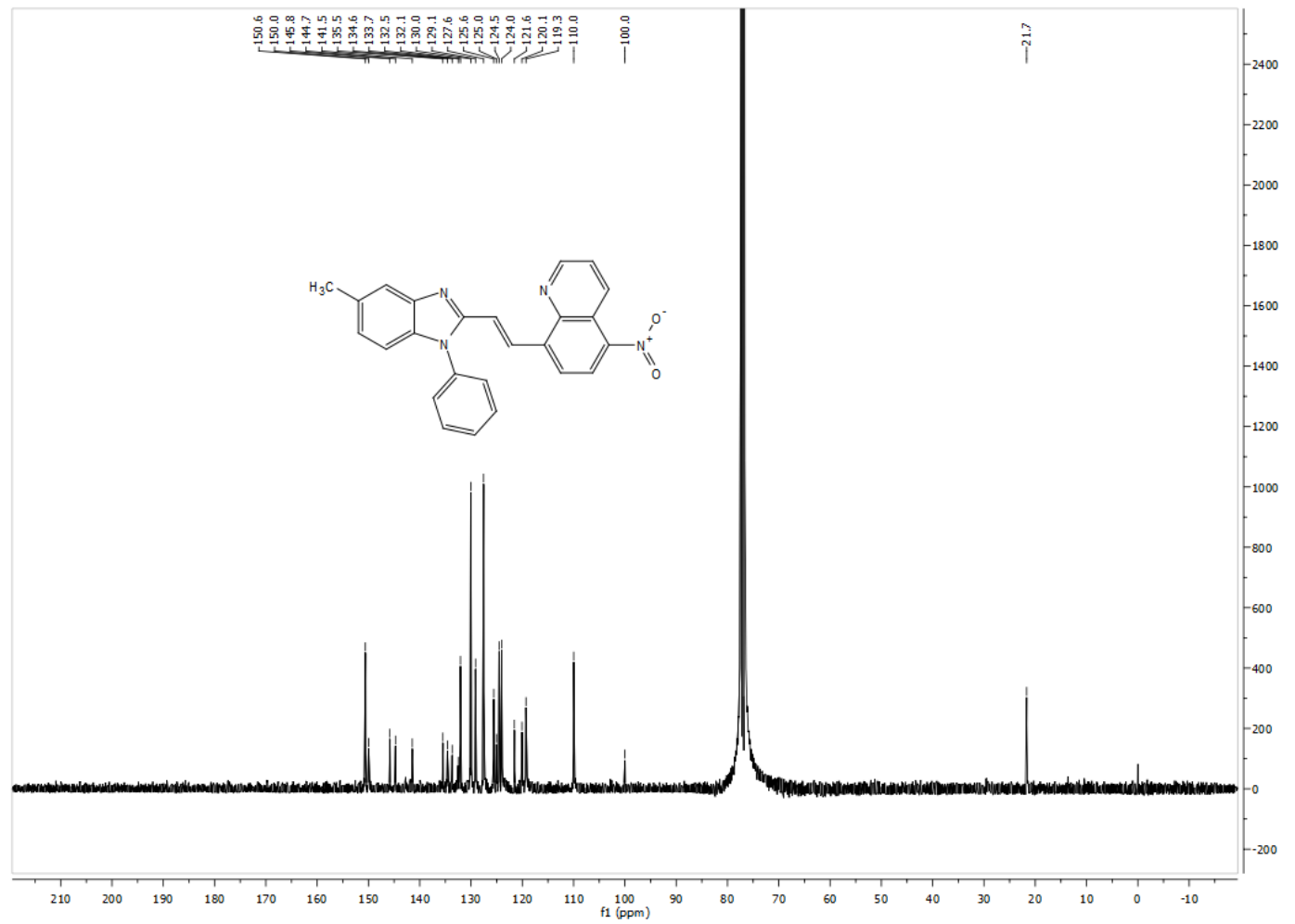


${ }^{1} \mathrm{H}$ NMR of BVQ1813

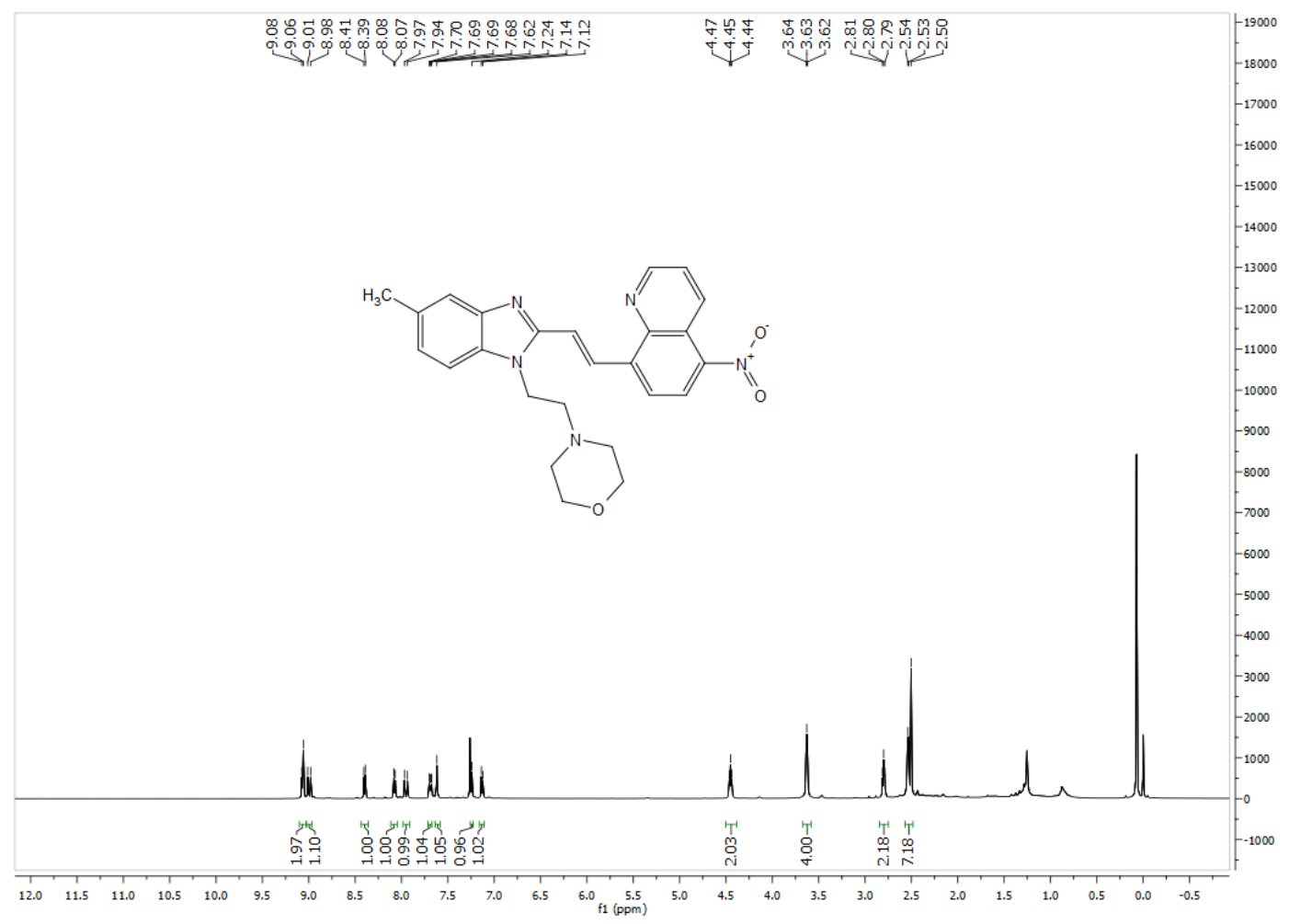

${ }^{13}$ C NMR of BVQ1813

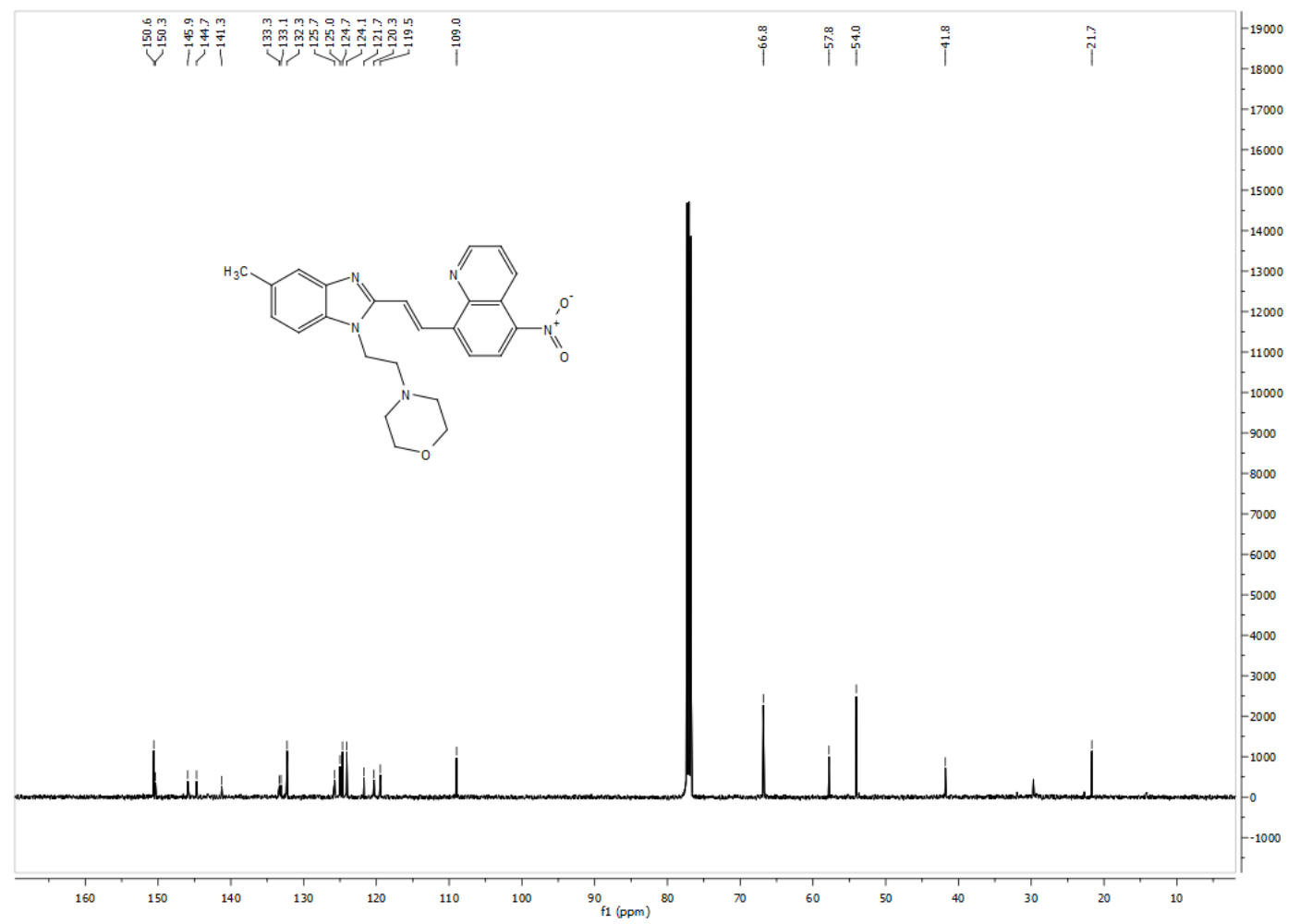




\section{${ }^{1} \mathrm{H}$ NMR of BVQ1814}

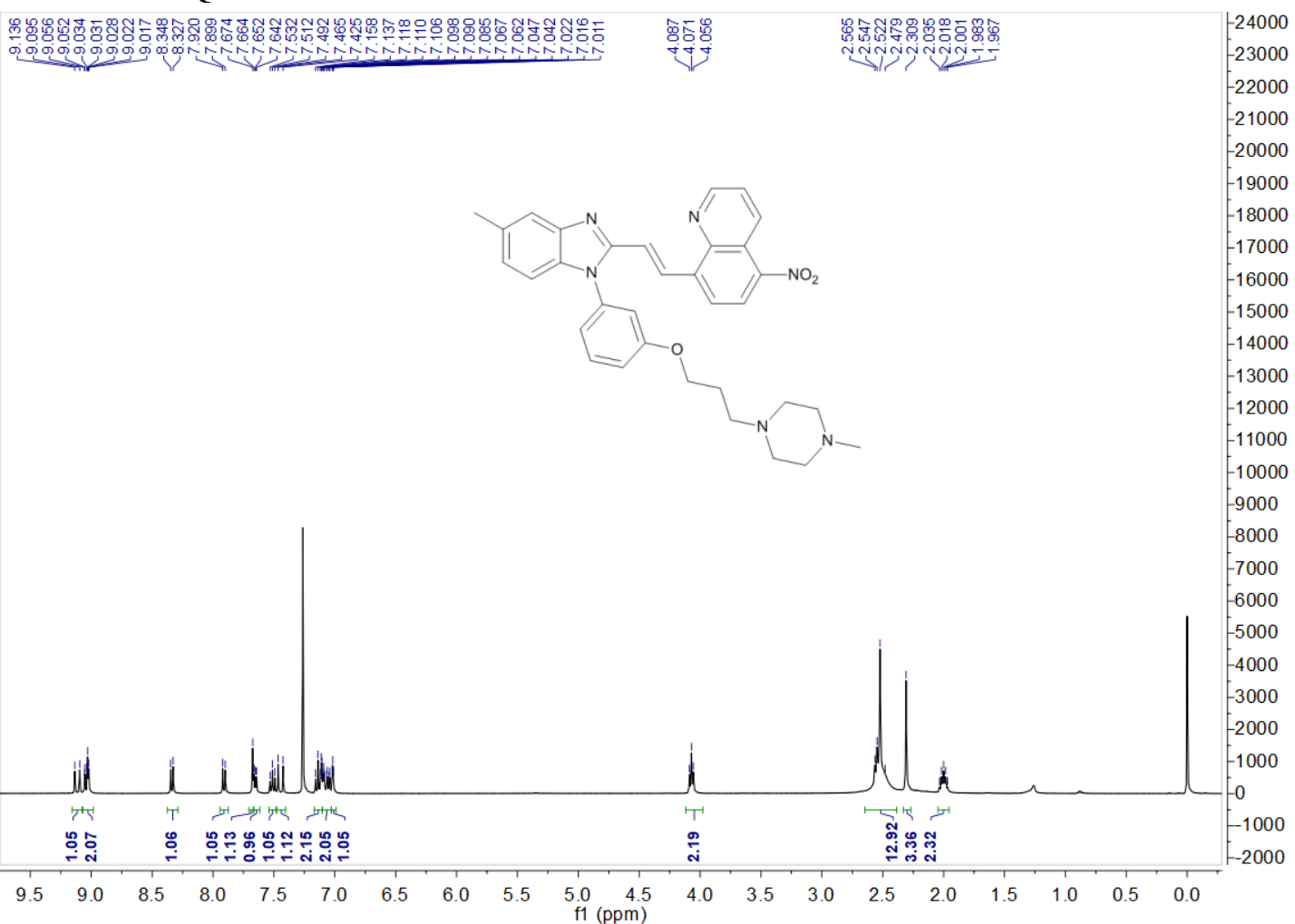

${ }^{13} \mathrm{C}$ NMR of BVQ1814

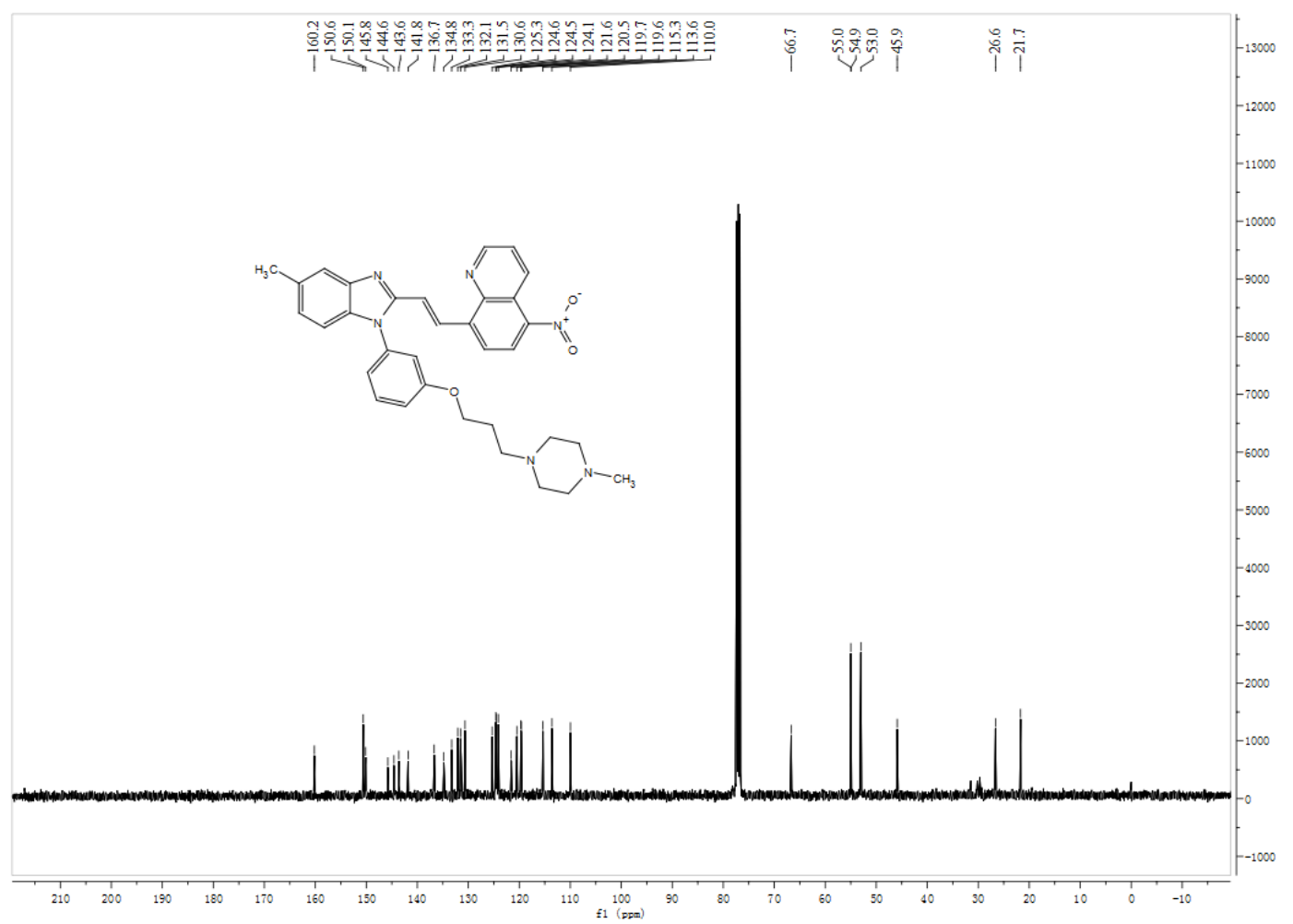


${ }^{1} \mathrm{H}$ NMR of BVQ1815

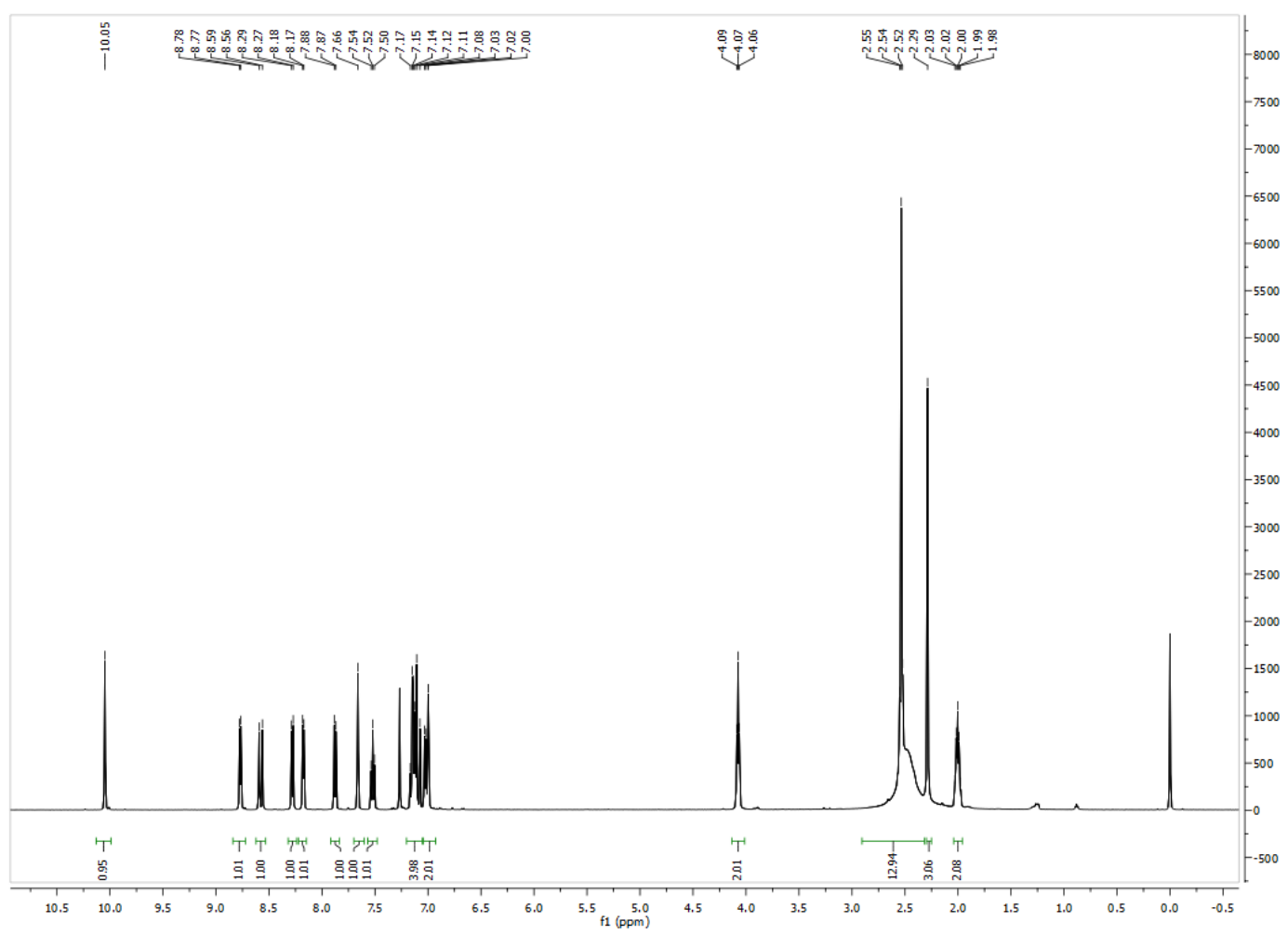

${ }^{13} \mathrm{C}$ NMR of BVQ1815

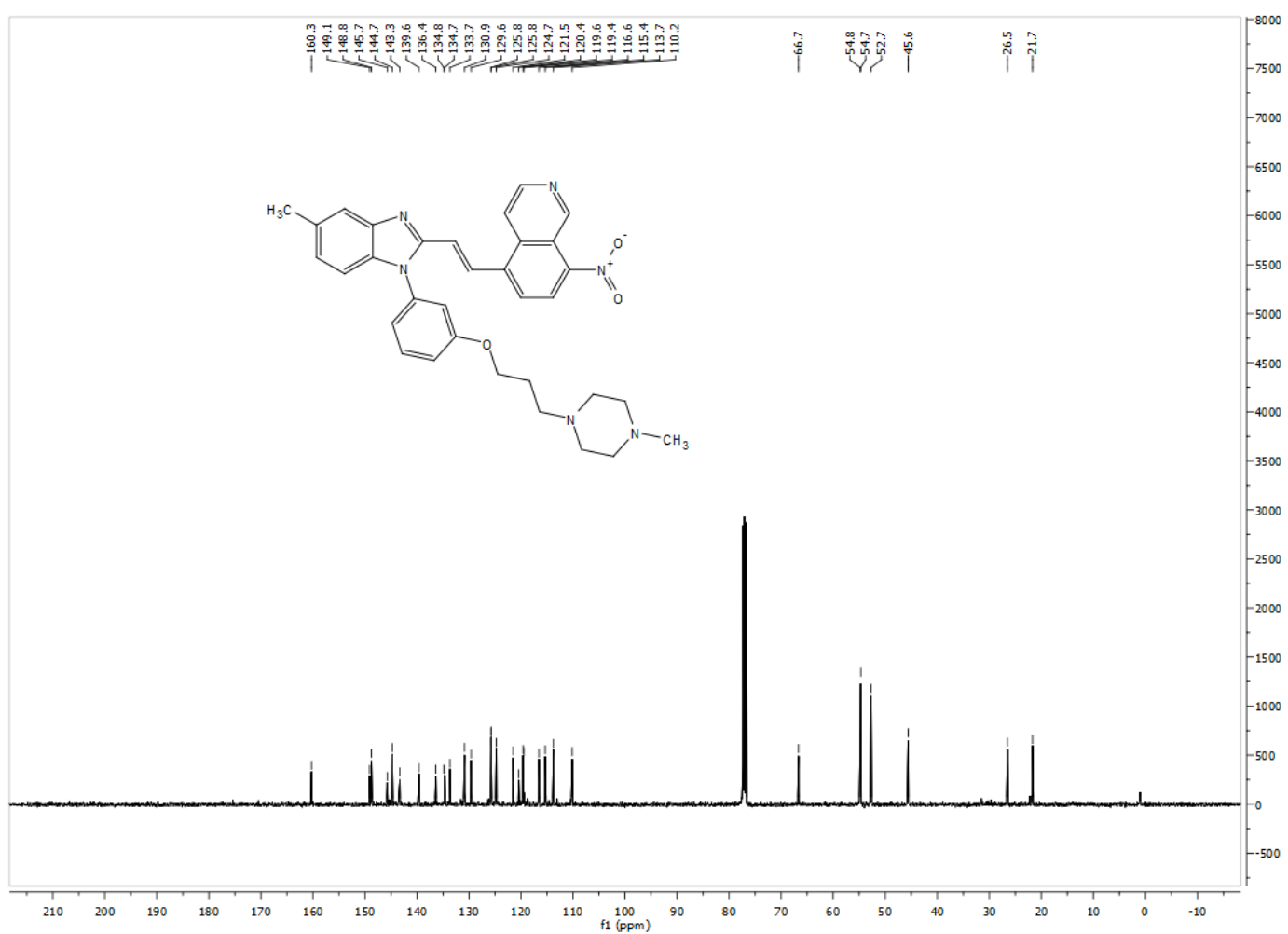


HRMS spectra of BVQ1812

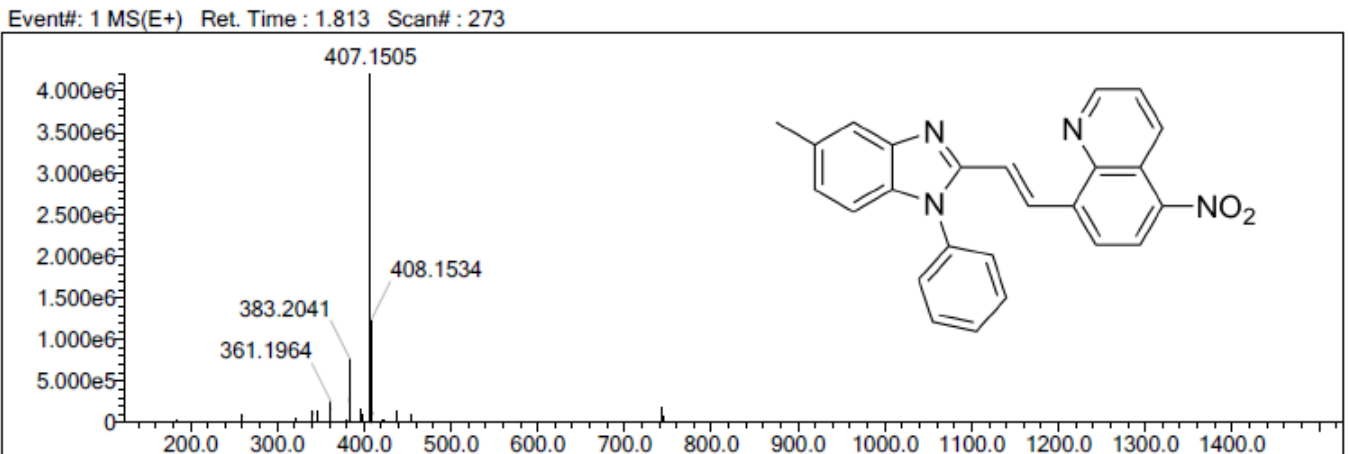

Measured region for $407.1505 \mathrm{~m} / \mathrm{z}$

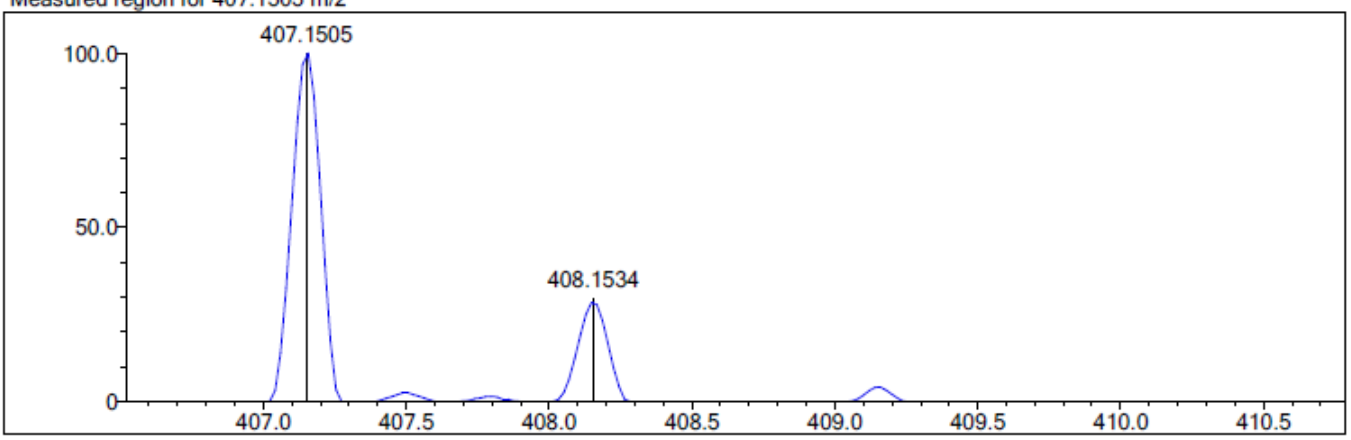

$\mathrm{C} 25 \mathrm{H} 18 \mathrm{~N} 4 \mathrm{O} 2[\mathrm{M}+\mathrm{H}]+$ : Predicted region for $407.1503 \mathrm{~m} / \mathrm{z}$

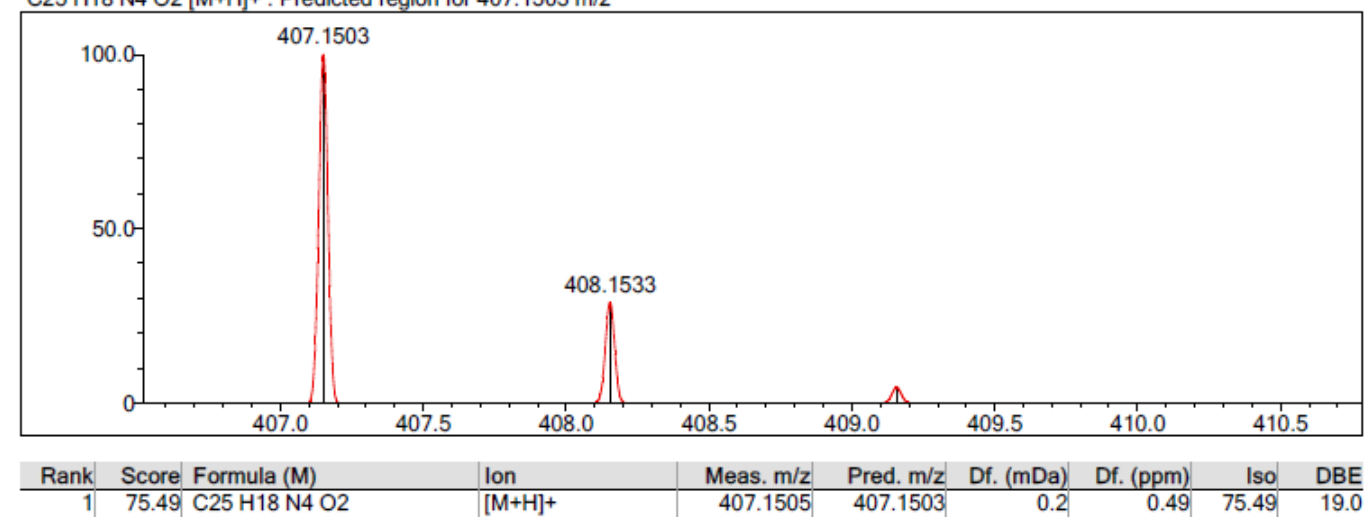


HRMS spectra of BVQ1813

Event\#: $1 \mathrm{MS}\left(\mathrm{E}^{+}\right)$Ret. Time : $0.560 \mathrm{Scan \#} \mathrm{:} 85$

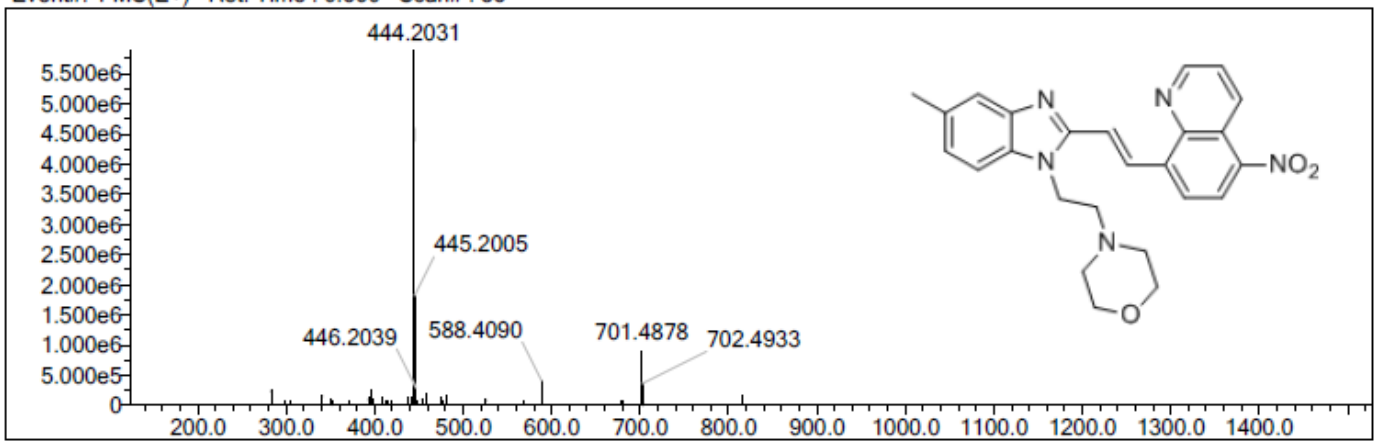

Measured region for $444.2031 \mathrm{~m} / \mathrm{z}$

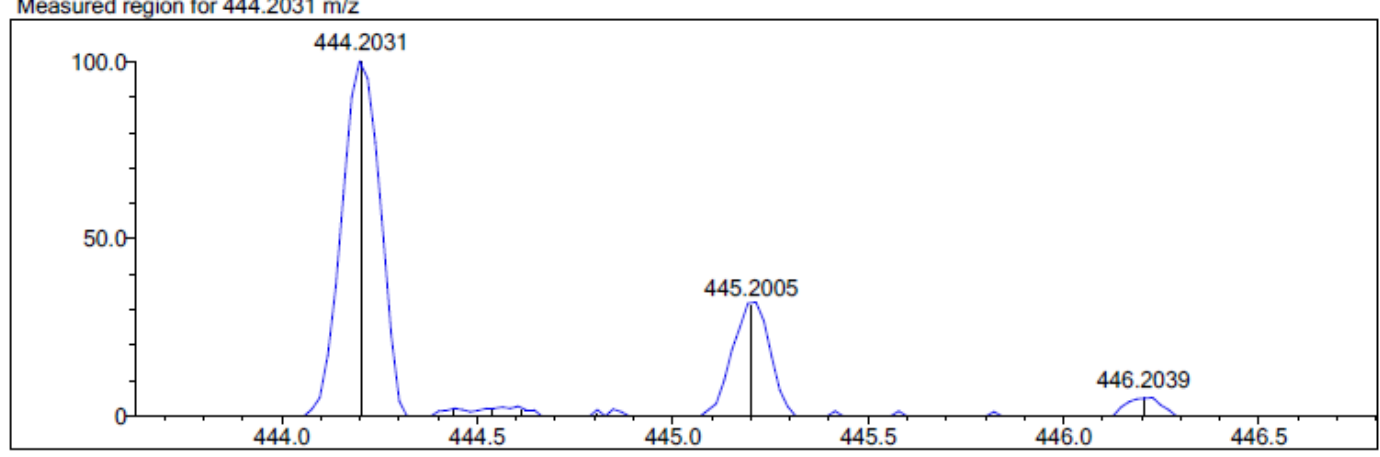

$\mathrm{C} 25 \mathrm{H} 25 \mathrm{~N} 5 \mathrm{O} 3[\mathrm{M}+\mathrm{H}]+$ : : Predicted region for $444.2030 \mathrm{~m} / \mathrm{z}$

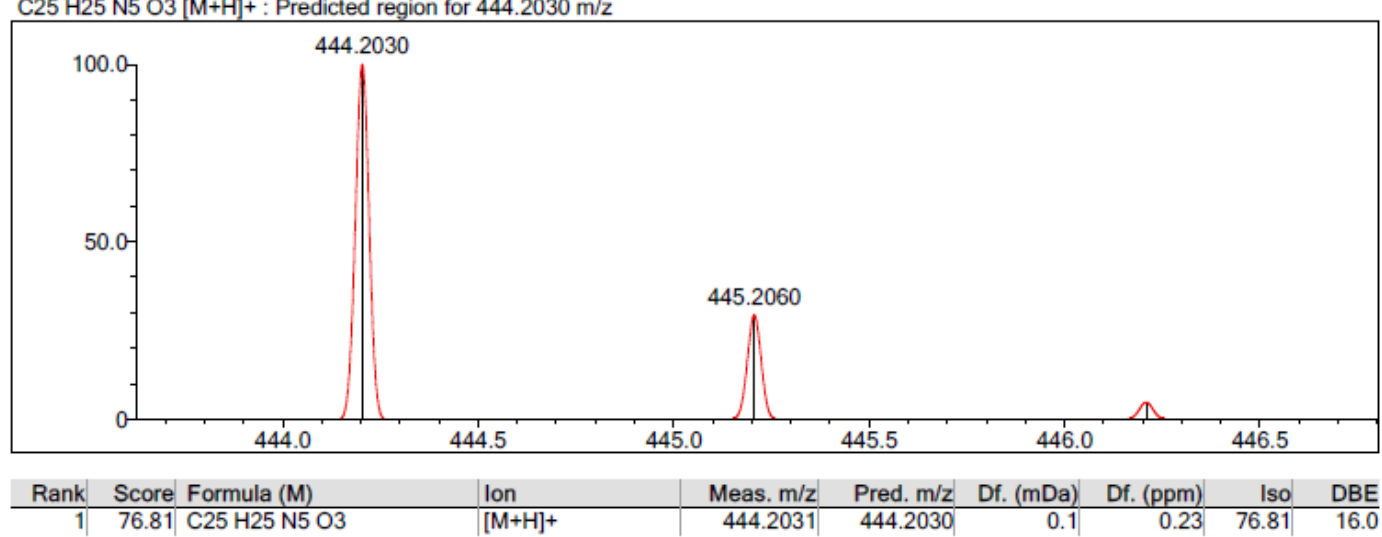


HRMS spectra of BVQ1814

Event\#: $1 \mathrm{MS}(\mathrm{E}+)$ Ret. Time : 0.640 Scan\# : 97

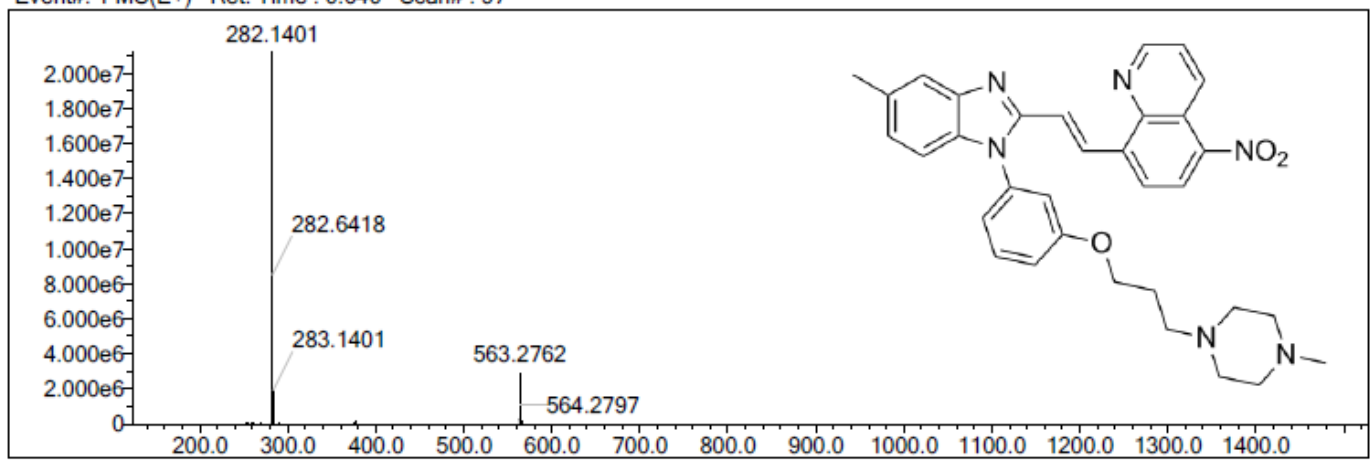

Measured region for $563.2762 \mathrm{~m} / \mathrm{z}$

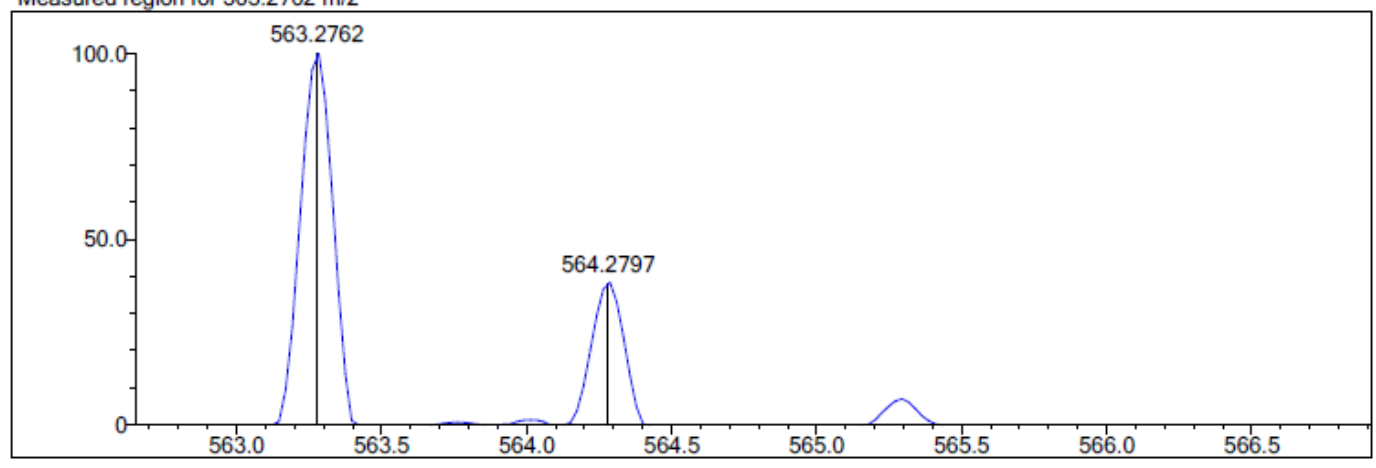

$\mathrm{C} 33 \mathrm{H} 34 \mathrm{N6} \mathrm{O} 3[\mathrm{M}+\mathrm{H}]+$ : Predicted region for $563.2765 \mathrm{~m} / \mathrm{z}$

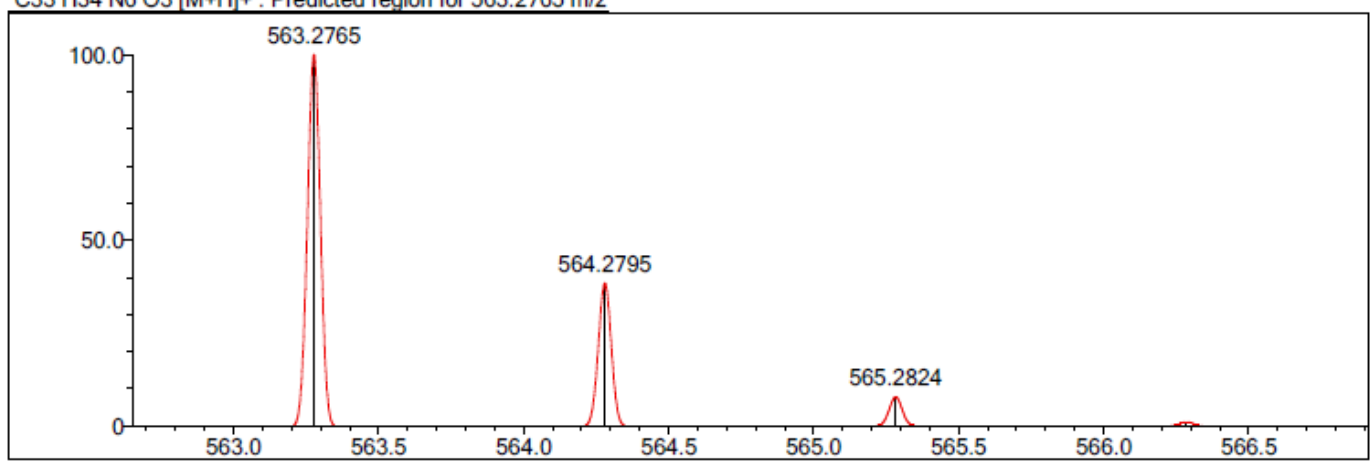

Rank Score Formula (M) 565.5 $2 \quad 91.91 \mathrm{C} 33 \mathrm{H} 34 \mathrm{~N} 6 \mathrm{O} 3$ 
HRMS spectra of BVQ1815

Event\#: $1 \mathrm{MS}(\mathrm{E}+)$ Ret. Time : 1.360 Scan\# : 205

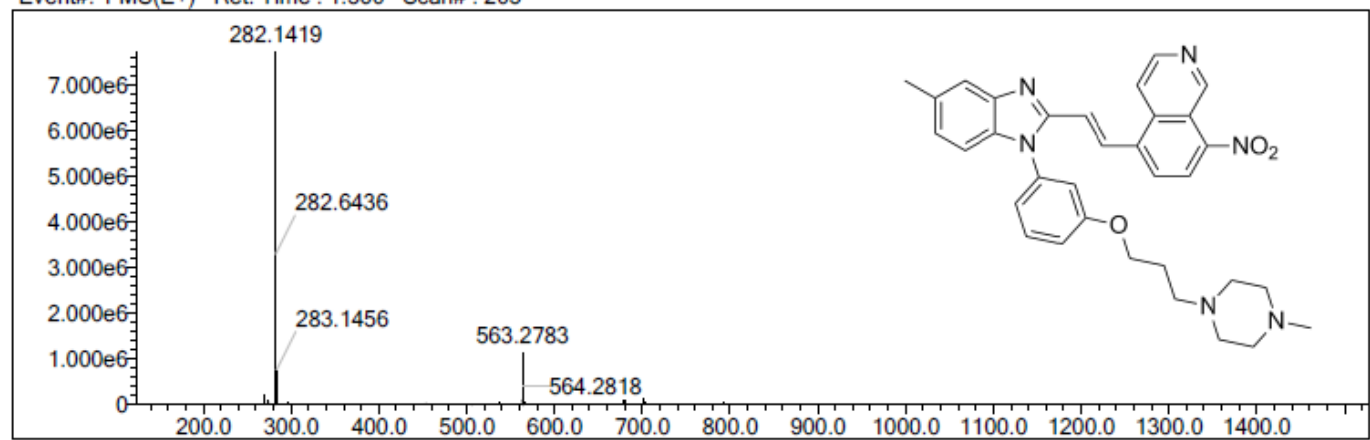

Measured region for $563.2783 \mathrm{~m} / \mathrm{z}$

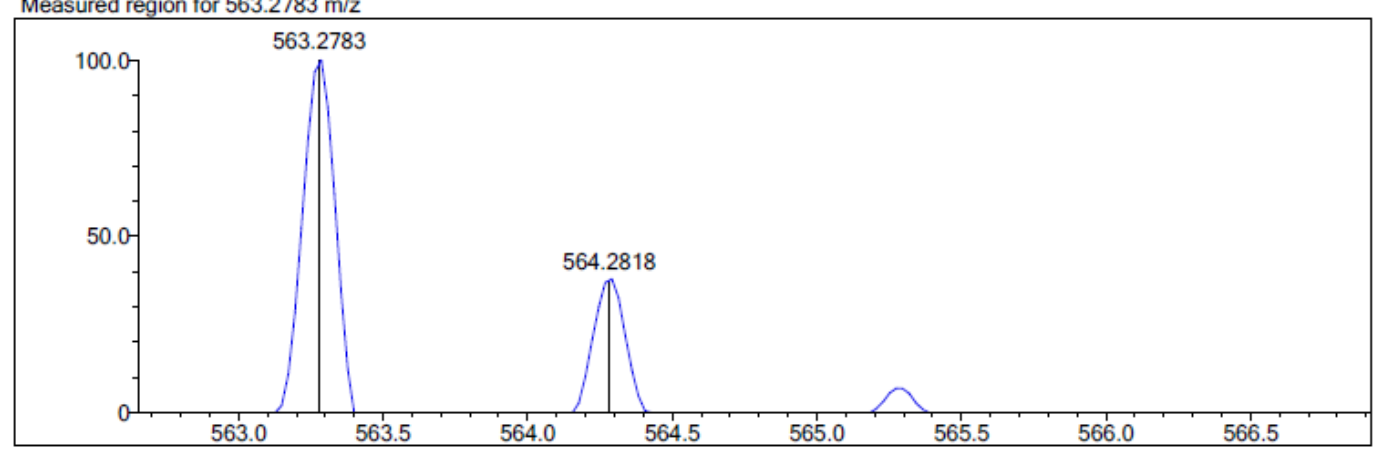

C33 H34 N6 O3 [M+H] + : Predicted region for $563.2765 \mathrm{~m} / \mathrm{z}$

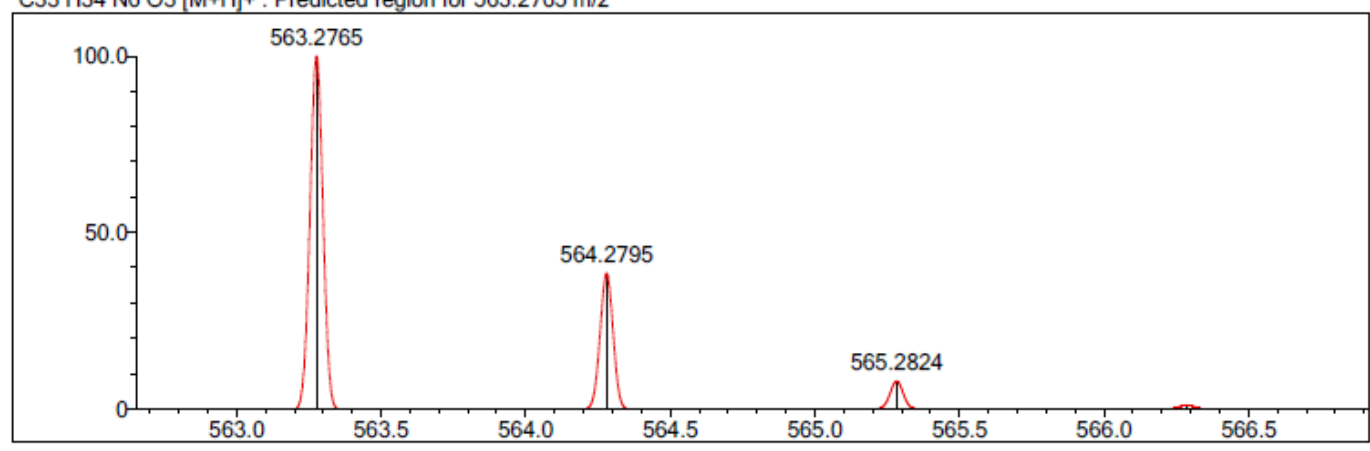

Rank Score Formula (M)

$2 \quad 89.56$ C33 H34 N6 O3

Ion

565.5

66.5

\begin{tabular}{rrr} 
Meas. $\mathrm{m} / \mathrm{z}$ & Pred. $\mathrm{m} / \mathrm{z}$ & Df. $(\mathrm{mDa})$ \\
\hline 563.2783 & 563.2765 & 1.8
\end{tabular}

\begin{tabular}{rrr} 
& IsO & DBE \\
\hline 3.20 & 94.78 & 20.0
\end{tabular} 
HPLC Spectrum of BVQ1814

mV

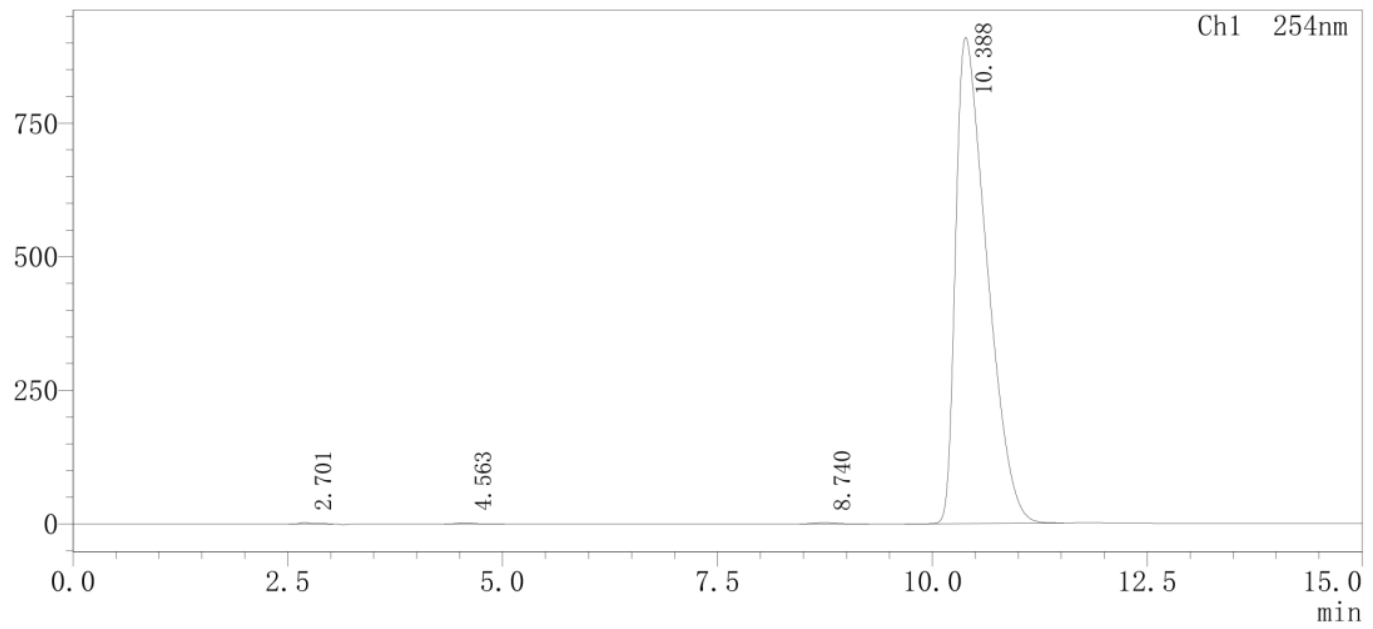

$\mathrm{mV}$

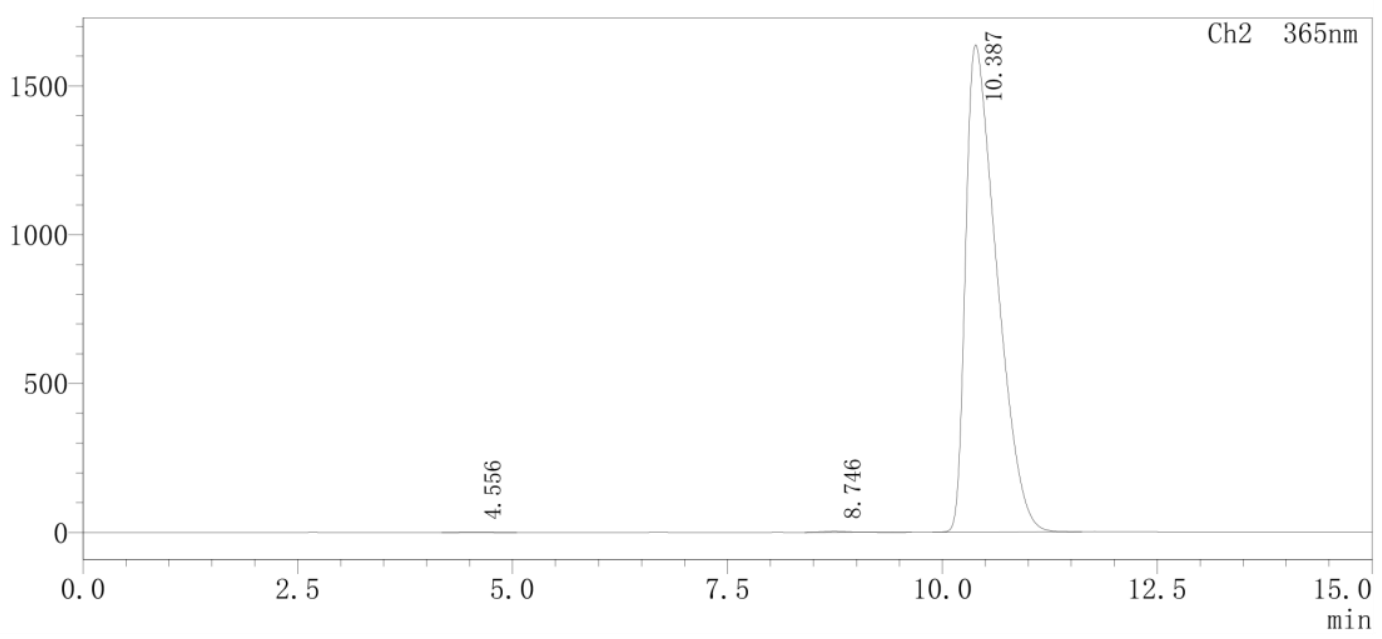

〈Peaks >

Ch1 254nm

\begin{tabular}{|r|r|r|r|r|r|r|r|}
\hline No. & Time (min) & \multicolumn{1}{|c|}{ Area } & \multicolumn{1}{|c|}{ Hight } & Percentage & Unit & Tag & Compound \\
\hline 1 & 2.701 & 31341 & 2458 & 0.135 & & $\mathrm{M}$ & \\
\hline 2 & 4.563 & 23587 & 1678 & 0.102 & & $\mathrm{M}$ & \\
\hline 3 & 8.740 & 41938 & 2125 & 0.181 & & $\mathrm{M}$ & \\
\hline 4 & 10.388 & 23075494 & 910239 & 99.582 & & $\mathrm{M}$ & \\
\hline Total & & 23172361 & 916500 & & & & \\
\hline
\end{tabular}

Ch2 365nm

\begin{tabular}{|r|r|r|r|r|r|r|r|}
\hline No. & Time (min) & \multicolumn{1}{|c|}{ Area } & \multicolumn{1}{|c|}{ Hight } & Percentage & Unit & Tag & Compound \\
\hline 1 & 4.556 & 19016 & 1249 & 0.046 & & $\mathrm{M}$ & \\
\hline 2 & 8.746 & 71488 & 3763 & 0.173 & & $\mathrm{M}$ & \\
\hline 3 & 10.387 & 41318779 & 1636111 & 99.781 & & $\mathrm{M}$ & \\
\hline Total & & 41409283 & 1641124 & & & & \\
\hline
\end{tabular}




\section{References}

(1) Huang, Y.-Y., Yu, Y.-F., Zhang, C., Chen, Y., Zhou, Q., Li, Z., Zhou, S., Li, Z., Guo, L., Wu, D., Wu, Y. and Luo, H.-B. (2019) Validation of phosphodiesterase-10 as a novel target for pulmonary arterial hypertension via highly selective and subnanomolar inhibitors, J. Med. Chem. 62, 3707-3721.

(2) Kunitomo, J., Yoshikawa, M., Fushimi, M., Kawada, A., Quinn, J. F., Oki, H., Kokubo, H., Kondo, M., Nakashima, K., Kamiguchi, N., Suzuki, K., Kimura, H. and Taniguchi, T. (2014) Discovery of 1-[2-Fluoro-4(1H-pyrazol-1-yl)phenyl]-5-methoxy-3-(1-phenyl-1H-pyrazol-5-yl)pyridazin-4(1H)-one (TAK-063), a highly potent, selective, and orally active phosphodiesterase 10A (PDE10A) inhibitor, J. Med. Chem. 57, 9627-9643.

(3) Yang, Y., Zhang, S., Zhou, Q., Zhang, C., Gao, Y., Wang, H., Li, Z., Wu, D., Wu, Y., Huang, Y.-Y., Guo, L. and Luo, H.-B. (2020) Discovery of highly selective and orally available benzimidazole-based phosphodiesterase 10 inhibitors with improved solubility and pharmacokinetic properties for treatment of pulmonary arterial hypertension, Acta Pharm. Sin. B 10, 2339-2347.

(4) Jain, A. N. (2003) Surflex: fully automatic flexible molecular docking using a molecular similaritybased search engine, J. Med. Chem. 46, 499-511.

(5) Wu, D., Huang, Y., Chen, Y., Huang, Y.-Y., Geng, H., Zhang, T., Zhang, C., Li, Z., Guo, L., Chen, J. and Luo, H.-B. (2018) Optimization of chromeno[2,3-c]pyrrol-9(2H)-ones as highly potent, selective, and orally bioavailable PDE5 inhibitors: structure-activity relationship, $\mathrm{X}$-ray crystal structure, and pharmacodynamic effect on pulmonary arterial hypertension, J. Med. Chem. 61, 8468-8473.

(6) Yu, Y.-F., Zhang, C., Huang, Y.-Y., Zhang, S., Zhou, Q., Li, X., Lai, Z., Li, Z., Gao, Y., Wu, Y., Guo, L., Wu, D. and Luo, H.-B. (2020) Discovery and Optimization of chromone derivatives as novel selective phosphodiesterase 10 inhibitors, ACS Chem. Neurosci. 11, 1058-1071. 